\title{
The role of prediction in social neuroscience
}

\author{
Elliot C. Brown ${ }^{1,2 *}$ and Martin Brüne ${ }^{1,2}$ \\ 1 Research Department of Cognitive Neuropsychiatry and Preventative Medicine, LWL University Hospital Bochum, Bochum, Germany \\ 2 International Graduate School of Neuroscience, Ruhr University Bochum, Bochum, Germany
}

\section{Edited by:}

Christian Bellebaum, Ruhr

University Bochum, Germany

Reviewed by:

Xiaolin Zhou, Peking University,

China

Inti Brazil, Donders Institute for

Brain Cognition and Behaviour,

Netherlands

\section{${ }^{*}$ Correspondence:}

Elliot C. Brown, Research Department of Cognitive

Neuropsychiatry and Preventative

Medicine, LWL University Hospital

of Ruhr University Bochum,

Alexandrinenstrasse 1-3,

Bochum 44791, Germany.

e-mail: elliot.c.brown@gmail.com
Research has shown that the brain is constantly making predictions about future events. Theories of prediction in perception, action and learning suggest that the brain serves to reduce the discrepancies between expectation and actual experience, i.e., by reducing the prediction error. Forward models of action and perception propose the generation of a predictive internal representation of the expected sensory outcome, which is matched to the actual sensory feedback. Shared neural representations have been found when experiencing one's own and observing other's actions, rewards, errors, and emotions such as fear and pain. These general principles of the "predictive brain" are well established and have already begun to be applied to social aspects of cognition. The application and relevance of these predictive principles to social cognition are discussed in this article. Evidence is presented to argue that simple non-social cognitive processes can be extended to explain complex cognitive processes required for social interaction, with common neural activity seen for both social and non-social cognitions. A number of studies are included which demonstrate that bottom-up sensory input and top-down expectancies can be modulated by social information. The concept of competing social forward models and a partially distinct category of social prediction errors are introduced. The evolutionary implications of a "social predictive brain" are also mentioned, along with the implications on psychopathology. The review presents a number of testable hypotheses and novel comparisons that aim to stimulate further discussion and integration between currently disparate fields of research, with regard to computational models, behavioral and neurophysiological data. This promotes a relatively new platform for inquiry in social neuroscience with implications in social learning, theory of mind, empathy, the evolution of the social brain, and potential strategies for treating social cognitive deficits.

Keywords: predictive coding, social interaction, forward models, prediction error, sensorimotor control, social learning, imitation, social decision-making

\section{INTRODUCTION}

"Engage people with what they expect; it is what they are able to discern and confirms their projections. It settles them into predictable patterns of response, occupying their minds while you wait for the extraordinary moment - that which they cannot anticipate."

Sun Tzu, The Art of War.

It has long been known by military strategists, psychologists, and neuroscientists that surprise and uncertainty can occur at a high cost. We live in an uncertain world full of ambiguous stimuli and events of which we are not sure of. Preparedness promotes efficiency, and this is true not only of behavior, but is also reflected in representations of an optimized neural system. For the brain to be energetically efficient and for our behavior to be optimal and adaptive, we utilize knowledge from our previous experiences to make predictions about the future and minimize the cost of surprise (Friston et al., 2006). In the animal kingdom, such previous experiences are often pre-programmed or innate through the forces of natural and sexual selection, that is, the flexibility of the prediction process is small. In "higher" mammals such as primates, pre-programmed patterns also exist (Tinbergen,
1951). However, due to the complexity and variability of the environment, the prediction mechanisms are much more plastic, and the programmes more open to personal (ontogenetically acquired) experience (Mayr, 1974). The brain's attempts to minimize the discrepancy between expectations or predictions and actual experience, addresses the problem of uncertainty and optimality, while also providing a common fundamental principle for processing incoming sensory information in our environment (Friston, 2005). The ideas just expressed here illustrate a generalized description of the role of prediction in cognition and the brain, and is becoming the consensus on a general and universal principle of how the brain works. Expectation, prediction, inference, anticipation, foresight, prospection, forecasting, and preparation are all terms that have been used to refer to different types of predictive processes that occur in the brain, in cognition and are evident in overt behavior. Predictive processing can refer to any psychological or neural process that utilizes estimations about the future. The proposal of the "predictive brain" broadly states that we are constantly generating mental representations to predict future states of the world around us, and about our own future internal mental state (e.g., Bar, 2007). These predictions of the future can include short-term estimations about upcoming 
events in one's current situation, and also long-term prospections about the likelihood of events occurring in the distant future, outside of our currently situated environment. It is thought that these predictive internal representations of the future are constantly compared with the actual perceived outcome of internal mental and external events. We must be able to process our errors to learn from our mistakes, and consequently update internal representations of the predicted future. This allows us to learn from our previous experiences. Many authors have implied that predictive and inferential processes underlie a wide range of cognitive processes, including, most prominently, motor control (Wolpert and Miall, 1996), perceptual inference (Friston and Kiebel, 2009) and reward-based associative learning (Schultz and Dickinson, 2000).

Social neuroscience seeks to find the underlying neural mechanisms responsible for social behavior. To successfully navigate ourselves through the social world, we must be able to understand socially relevant stimuli, make interpretations about their meaning and behave according to decisions that are accurate, optimal, and adaptive. This includes understanding others' minds, and their intentions and beliefs. Inference and estimation is essential to social understanding, particularly as social scenarios are riddled with complex circumstances filled with ambiguity and uncertainty. The central role of predictive mechanisms in motor control, perception, and learning are clearly evident and welldocumented, though a fast-growing body of experimental and theoretical work is providing increasing evidence of how such predictive mechanisms are also embedded in social cognitive processes. Shared neural representations of one's own experience and the experience of others' lies at the heart of this work (Decety and Sommerville, 2003). Similar neural activity has been revealed in the observer when both experiencing and observing actions (Gallese et al., 1996), rewards (Marco-Pallares et al., 2010), and emotions such as fear (Olsson et al., 2007) and pain (Cheng et al., 2008). The interpersonal connection of shared experience, as also represented by shared neural representations, is likely to form the basis for high-level social cognitions such as empathy (Decety and Ickes, 2009). Although it is still not as clear as to what degree predictive mechanisms may underlie social cognitions and how predictive mechanisms drive processing during social perception, social understanding, social interaction, and social learning. Numerous conceptualizations of predictive mechanisms have been made to account for different psychological and neural phenomena, each with their own specification of what prediction is, and how it is generated and utilized. The increasing popularity and support for the concept of a "predictive brain" calls for further discussion about whether this framework can be extended to other domains such as social cognition, and especially where conceptual boundaries between specifications may lie.

Given the broad scope of the implications of prediction in fundamental cognitive and neural processes, and in light of the evidence that in primates the complexity of the social environment has been a major driving force of cognitive evolution, it follows that predictive mechanisms are likely to both underlie and modulate processes involved in social cognition and social interaction. The aim of this article is to highlight recent theoretical and empirical work that is at the interface of the "predictive brain" and the "social brain." Our article is intended to propose extensions of predictive mechanisms of fundamental cognitive processes into the context of social cognitions. The goal is to highlight the potential for operationalizing social cognitive processes in predictive coding frameworks and related predictive mechanisms. The hope is that this will promote further discussion on the potential for extending current predictive frameworks in action, perception, and learning to cognitions required for socially relevant cognitive processes.

\section{THE PREDICTIVE BRAIN}

Before discussing the relationship between the predictive brain and the social brain, some crucial points will be introduced, which are particularly relevant to the issues related to social cognition. The terminology used to label different predictive processes can determine the definition of the mechanisms being referred to, and therefore it is important, for this article and for future work exploring this topic, to provide operational definitions of the terms being used. The mathematical methods on which computational models representing neural activity and behavior are built upon provide the basis for the application of the principles of predictive coding. The basics of the role of prediction in perception, action, and learning will also be introduced here.

\section{PREDICTION, INFERENCE, AND SIMULATION}

We can roughly distinguish between three main predictive concepts that are relevant to different aspects of the predictive social brain; these are inference, prediction, and simulation. Inference can refer to deterministic short-term processes that are largely situated in current behavior and are probabilistic estimations about the state of the world, and are most relevant to prediction errors and concepts modeled with Bayesian statistics (Friston et al., 2009). In contrast, the term "prediction" is generally more relevant to long-term prospections made about the potential for distant future events to occur. Simulation can be stated as a constructed internal representation of imagined events (Gilbert and Wilson, 2007) based on episodic memory (Williams et al., 1996). This can include processes such as scene construction that retrieves and integrates previous experiences to form a coherent event or mental image (Schacter and Addis, 2007), and is somewhat autobiographical in nature (Buckner and Carroll, 2007). Related to this is the framework of the predictive brain from Barsalou (2009) who describes simulation as a "re-enactment of perceptual, motor, and introspective states (e.g., affect, motivation, intentions, metacognition, etc.)". For the sake of integration, but without intended overgeneralization, the use of the term "predictive mechanisms" in this article does not only refer to higher-level long-term prospections about the future, but are also inclusive of the more fundamental lowlevel short-term predictive processes of inference, such as those conceptualized in Bayesian predictive coding formulations of action and perception. The frequent lack of consistency in the previous use of these terms reflects a need for further specification of what they imply, though the use of these terms are clarified operationally in this article according to the context discussed. 


\section{BAYESIAN INFERENCE}

To introduce the concept of the predictive brain, it is important to mention the basic principles behind Bayesian statistics, as this underlies many of the predictive coding frameworks in perception, action, and learning. Bayesian statistical inference is a mathematical method of inference which incorporates priors, or prior beliefs learned from previous experiences that generate internal models of a predicted outcome, and consequently act as top-down modulators of bottom-up sensory input. This statistical method can be used to determine the probability of a certain outcome, given a predetermined assumption (i.e., the prior "belief" and the likelihood), which can then be subsequently updated according to the actual outcome. This is thought to be comparable to how the brain makes predictions about future outcomes in learning and motor control. An example of Bayesian inference states that we already have a prior belief of the probability of seeing either a white van or a white polar bear in the street, and thus the probability of receiving the visual input of a white van will be much higher than that of a white polar bear. While this example clearly relates to one's acquired knowledge, priors can also be innate. For example, visual perception experiments have shown that the recognition pattern of an object changes just by turning the image of the object by $180^{\circ}$, because animals have the built-in expectation that natural light comes from above (Schober and Rentschler, 1972). The Bayesian inferential approach can be used to create simulated models of neural activity. Substantial experimental evidence demonstrates that motor learning is performed by subjects in a Bayesian fashion (Kording and Wolpert, 2004) with probabilistic calculations being performed in the brain to predict future sensory consequences. This Bayesian predictive coding scheme has been applied to perceptual inference (Kiebel et al., 2009), perceptual learning (Friston, 2008), reinforcement learning (Friston et al., 2009), active inference (Friston et al., 2010), attentional processing (Feldman and Friston, 2010), and sensorimotor control (Wolpert and Miall, 1996).

\section{INFERENCE AND PREDICTION IN PERCEPTION AND ACTION}

It is clear that perception is not just a merely reactive process in which sensory input is received and registered, but is more likely a construction of predicted representations of the environment. The concept of generative internal models in perception was proposed many years ago, and represents another common principle that is at the basis of some predictive coding frameworks. The first experimental evidence found to support the proposal of predictive internal models of perception came from Sperry (1950), referring to a "corollary discharge," and von Holst and Mittelstaedt (1950) referring to an "efference copy." These were both set out to explain how we perceive a stable world despite rapid and frequent eye movements. In both perception and action, the efference copy creates a predicted internal ("forward") model of the sensory feedback according to the corresponding visual percept or motor action. The corollary discharge is then generated from this forward model and is then compared to the actual incoming sensory feedback, or afference, once transmitted from the peripheral sensory receptor to the brain. The matching process that occurs between the generative forward model, or corollary discharge, and the corresponding sensory feedback is thought to maintain the experience of stability in the ever-changing visual scene during eye movement. During motor control, the matching process between the generative forward model of the planned action and the sensory consequence of the action is thought to be the neural basis for distinguishing between self-generated and externally generated motor actions (Blakemore et al., 1998). Predictive coding in visual processing has been implemented in various hierarchical models (Rao and Ballard, 1999) that generally propose an integration of top-down expectancies and bottom-up sensory input reflecting stimulus information. Feedforward connections carry error signals, but in addition, cortical feedback connections transmit expectancy biases or predictions. A similar matching process is thought to occur during the execution of motor actions, and has been argued to be the underlying mechanism that maintains a sense of agency or ownership over our own motor actions. A mismatch, i.e., a discrepancy between the predictive forward model and the actual sensory feedback, can have pathological consequences, particularly relevant to schizophrenia and pathological abnormalities in ownership of action (Feinberg, 1978). This discrepancy between the expected and actual sensory outcome of a visual percept or motor action can also be referred to as a prediction error.

The coupling of action and perception is well-established, with the ideomotor framework even considering action and perception as inseparable, and fundamentally the same (Prinz, 1997). The ideomotor theory of action proposes that internal representations or images of actions are coupled to the execution of actions themselves, and that perceptual events associated with an action also initiates an internal representation of that action. [e.g., the theory of event coding (TEC) (Hommel et al., 2001)]. Frameworks for forward models of action have been formulated and operationalized in computational models, such as the MOSAIC model (Haruno et al., 2001), which rely on Bayesian inferential statistics. In such frameworks, "forward" refers to the causal direction from motor command into the corresponding sensory consequence, with the forward model ("predictor") being generated from the efference copy. An inverse model ("controller") represents the opposite direction, whereby desired sensory consequences are transformed into motor commands. Computational representations of forward models of action have been formulated with Bayesian statistics, with priors and their likelihood acting as predictive elements for the outcome of an action.

\section{PREDICTION IN LEARNING AND DECISION-MAKING}

Prediction also crucially guides learning through the updating of future estimations about the state of the world and probabilities of the likelihood of potential future events. Computing probabilistic predictions about the outcomes of one's own and others' actions is based on previously learned action-effect contingencies, i.e., the associative mapping between the action and the outcome. Reward prediction errors generated in dopaminergic neurons, are thought to encode the magnitude of the discrepancy between expected reward and experienced reward (Schultz and Dickinson, 2000) and therefore, drive decision-making. This reward prediction error acts as a teaching signal for updating expected reward value and is the neural basis for learning. Error processing, response monitoring, and cognitive control are also 
intrinsic to predictive processing (Hoffmann and Falkenstein, 2011), whereby errors are generated by the discrepancy between our predictions and the actual outcome, and allow us to learn from our mistakes. The neural substrate underlying the valuation of positive and negative feedback is largely founded upon the reward processing system in the brain.

\section{THE PREDICTIVE SOCIAL BRAIN}

Social interaction and social functioning involves a multitude of socially relevant cognitive processes including, to name a few, social perception, understanding others' actions, observational social learning, social decision-making, and empathy. Top-down influences of social information can directly drive how we process visual information. More evidence is emerging which suggests that a similar mechanism, or "shared neural representation" is used for understanding others' actions, whereby an internal model of others' actions allows us to make predictions about the consequence and outcome of an observed action, and consequently understand and interpret the goals and intentions of the action. Many authors have suggested how conceptualizations of fundamental cognitions such as learning, could be extended to explain mental processes required for social understanding, social interaction, and social learning (e.g., Rushworth et al., 2009). There is also substantial work to indicate that there is top-down influence of social information and social interaction on fundamental error processing, learning, and decision-making processes.

We now present neurophysiological and behavioral findings, and computational principles that point to an essential relevance of predictive mechanisms in a broad variety of social cognitive processes that may be intrinsic to motor, perceptual, and learning processes, and permeate different levels of processing. Numerous parallels are also drawn to illustrate how the basic principles in prediction, inference, and simulation in non-social contexts can be applied to social aspects of cognition.

\section{SOCIAL PERCEPTION AND SEEING OTHERS' ACTIONS}

Person perception can be described as the impressions or mental representations we form of others based on socially constructed information, for which the perception of actions and faces act as crucial cues, and which predictive mechanisms are likely to also play a central role. The superior temporal sulcus (STS) is involved in the perception of biological motion and in inferring the intentions or goals from biological motion (Perrett and Emery, 1994; Allison et al., 2000; Jellema et al., 2000), and has been implicated in the mirroring network (Molenberghs et al., 2010). When we observe others' actions, we can see activity in the STS and it is, therefore, likely related to the mirror system and possibly in determining whether movements have social relevance. A recent study used an fMRI repetition suppression paradigm to measure activity in the action observation network while watching a robot, an android, and a human move (Saygin et al., 2012). This study interestingly found neural activity that was distinctive for the mismatch between (human versus robotic) appearance and motion, which was proposed to reflect prediction error activity, possibly as an index of an expectancy violation. They also suggested that this mismatch prediction error signal could account for the "uncanny valley" in which androids are seen as strange and disconcerting if they are too human-like (Mori, 1970).

The STS also appears to have a role in face perception, and the perception of the dynamic features of a face (Haxby et al., 2000; Gobbini and Haxby, 2007; Ishai, 2008). An MEG study from Furl et al. (2007) found that evoked neuromagnetic fields, originating from the fusiform face area (FFA) and the STS, were modulated by adaptation to facial expressions, and that these predicted behavioral after-effects. They propose that this can be explained by experience-dependent coding, according to a predictive coding account, which consequently creates top-down biases in face perception. Another phenomenon of face perception, in which low level visual processes may be modulated by socially relevant factors, is the "other-race effect." People have been shown to be better at recognizing faces of their own race as opposed to other races (O'Toole et al., 1994; Meissner and Brigham, 2001), which appears to occur at the visual encoding stage of face processing (Walker and Tanaka, 2003). This effect could be accounted for by after-effects from visual adaptation to facial race categories (Webster et al., 2004) that is likely to be based on long-term expertise and learning processes (Rhodes et al., 1989; Stahl et al., 2010), and has been represented by hierarchical generative models in a predictive coding framework (Furl et al., 2007).

Social perception can refer broadly to high-level visual processing of socially relevant stimuli, though social factors can also influence low-level visual processing performance. One major challenge for theories of forward models of action is to demonstrate an inverse relationship in which motor behavior directly influences perception. It has been shown that synchronized and communicative interaction can influence visual discrimination performance (Neri et al., 2006), and improve visual detection of biological motion (Manera et al., 2011), respectively. Manera et al. (2011) explain their finding in terms of predictive coding in that one's own communicative gestures can predict the other's expected action. Bortoletto et al. (2011) found, with EEG event-related potentials (ERPs), that action plans and intentions of observed hand gestures can modulate ERPs associated with early visual processing of the observed actions. Motor training has been shown to directly modulate activity in the occipital lobe (Engel et al., 2008), and TMS over the ventral premotor cortex, but not the primary cortex suppressed a visual aftereffect when categorizing others' actions (Cattaneo et al., 2011). These studies demonstrate an early effect of social interaction on low-level visual processing, at an early stage of processing before awareness, therefore confirming the inverse relationship. Research on the neural processing associated with observing others' actions has received widespread interest in a broad range of research areas, particularly in the last 15 years, though there still seems to be some divergence in theoretical standpoints, which could potentially be bridged with a common dialog of predictive mechanisms.

\section{PREDICTION AND THE MIRROR SYSTEM}

The discovery of the activation of apparently functionally-specific "mirror neurons" in monkey premotor cortex during both action execution and action observation (Gallese et al., 1996) has led to broad speculations about their role in social cognition through 
action understanding. This hypothesis is compatible with simulation theories of theory of mind (e.g., Davies and Stone, 1995), which in general argues that individuals utilize simulations of their own actions, and consequently their own thoughts, intentions, beliefs, and emotions to predict the mental state of others and therefore, ascertain knowledge of other minds. It is thought that this then ultimately provides the fundamental elements for the ability of an individual to understand, and empathize with, the social behavior of others. Naturally, this has also revealed a number of controversies questioning the functional specificity of the mirror system (e.g., Hickok, 2009), and the anatomical validity of a human mirror system as originally specified (e.g., Molenberghs et al., 2009; Mukamel et al., 2010).

Some alternative models of the mirror neuron system have been put forward to try to deal with some of these issues and controversies. One, which is most relevant here, is a predictive coding account of the mirror neuron system (Kilner et al., 2007a,b) that uses a Bayesian framework for its implementation. It argues that an internal model is generated during action observation, which in turn transfers an action prediction through backwards connections, from frontal areas implicated in the mirror system, to action representations in the STS and parietal mirror areas, which then produces an action prediction error. As with other predictive systems, the brain seeks to minimize the prediction error. This has been demonstrated with simulations of handwriting that artificially produce electrophysiological responses to movement expectation violations (Friston et al., 2011). Another alternative account of the mirror system is based on associative learning (Heyes and Ray, 2000; Heyes, 2001), and argues that learned sensorimotor experiences, from self-observation and the observation of others, actually promote the formation and emergence of a mirror system, which is acquired and refined throughout development. The learned associations of action contingencies are thought to provide the basis for action understanding. This associative learning account is supported by findings related to expertise and familiarity of actions in motor cortex activity during action observation, and by studies showing neural activity outside of the mirror neuron system during observation of actions that are unfamiliar or difficult to understand (Brass et al., 2007; Kilner and Frith, 2008). Greater expertise and familiarity of observed actions induces greater activity in the action observation/mirror-neuron network in the brain (Calvo-Merino et al., 2005, 2006; Orgs et al., 2008). This is evident from both practicing a particular motor sequence and from passively observing actions (Cross et al., 2009). Automatic imitation and motor interference also appears to be influenced by previous sensorimotor experience (Capa et al., 2011). These findings lend themselves to an associative learning account of imitation and the mirror system (Catmur et al., 2009), whereby motor representations can be learned through observation (Hayes et al., 2010). Although it is likely that the coding of motor sequences for observed and practiced actions differs (Gruetzmacher et al., 2011), though this is still an elusive, but crucial issue in conceptualizations of imitation and action observation.

The only known single neuron recordings of the proposed mirror system in the human brain comes from Mukamel et al. (2010), who intriguingly found activity in the hippocampus, an area never before included in the classical mirror system. The involvement of the hippocampus in a mirror neuron network could potentially be accounted for by Bar's (2009) proposal of the predictive brain with memory "scripts" as predictions, and by Barsalou's (2009) suggestion of the involvement of long-term memory in simulation and perceptual prediction, which may not have been detected previously with fMRI techniques. Bar presents an integrated framework of perception and cognition that argues that memory "scripts," generated through learned associations from previously real and imagined experiences, form the basis for predictions of what is about to come next in our environment. It is also suggested that this association-based prediction framework can be applied to prediction in social interactions (Bar, 2007; Bar et al., 2007). By taking an inference-based account of the mirror neuron system, this allows for the integration of Bar and Barsalou's frameworks into the realm of social cognition, action understanding, and the mirror neuron hypothesis.

These accounts of the mirror neuron system highlight the potential role of predictive mechanisms, particularly simulation, and inference with the predictive coding, and associative learning accounts, in social interaction. Consequently, these accounts could legitimately be extended to highlight the role of prediction, simulation and inference in other non-motor social cognitions associated with mirror neuron activity. Inferencebased accounts of the mirror neuron system could potentially apply to some examples of work in social neuroscience showing that mirror neuron activity has been implicated in the distinction between self and other (Sinigaglia and Rizzolatti, 2011), mentalizing (De Lange et al., 2008; Centelles et al., 2011) and simulation of emotions (Bastiaansen et al., 2009). Even though the mirror neuron hypothesis provides a very appealing explanation for the processing of others' actions, there are other theories also related to predictive mechanisms that propose integrative frameworks for sensorimotor control and social interaction.

\section{FORWARD MODELS OF ACTION AND SOCIAL INTERACTION}

Forward models of action and the corollary discharge are thought to be crucial in determining ownership of action, or sense of agency, and being able to distinguish between self and other by distinguishing between self-generated actions and movements generated by external forces (Fourneret et al., 2001; Franck et al., 2001; Knoblich et al., 2004; Yomogida et al., 2010). Numerous studies have shown that our sense of agency for our actions can be disturbed if there is a discrepancy in visuomotor perception between expected and intended actions (Daprati et al., 1997; Franck et al., 2001; Van den Bos and Jeannerod, 2002). One recent study demonstrating this found that a pre-reflective or implicit sense of agency can be influenced by the accuracy of sensorimotor predictions (Gentsch and Schutz-Bosbach, 2011). The ability to distinguish between self and other is a fundamental prerequisite for many social cognitive processes required for understanding others.

A corollary discharge has also been proposed to be present in the speech system, and is therefore, suggested to be responsible for attributing self-generated speech as one's own (Ford and Mathalon, 2004). Evidence mostly comes from ERP work 
on occasions when a disturbance in the corollary discharge occurs, which is relevant to symptoms seen in schizophrenia, particularly with auditory hallucinations. This auditory corollary discharge may also therefore, contribute to establishing the distinction between self and other in verbal communication. A recent study used MEG to compare valid and invalid predictions made between visual speech input and auditory speech signals (Arnal et al., 2011). From their results, they inferred that top down predictions were coded by slower frequencies of neural activity, whereas prediction errors in audiovisual speech were reflected by high frequency ranges. In a social interactive setting, i.e., during natural verbal communication, Stephens et al. (2010) found that spatiotemporal brain activity of the speaker and the listener became synchronized, and the greater this coupling, the greater the understanding. The findings also revealed anticipatory neural responses in the listener, particularly in the striatum, medial prefrontal cortex (MPFC) and dorsolateral prefrontal cortex (DLPFC), areas that also encode the reward prediction error and value representation.

An extension of one forward model framework of action, the MOSAIC model, has been applied to explain social interaction (Wolpert et al., 2003). The model parallels the sensorimotor loop between the forward model and the incoming sensory information, with the social interactive loop being between self-generated and observed communicative actions. Communicative actions are thought to be generated from the motor commands observed by a confederate, which consequently causes changes in the observer's mental state, which in turn initiates communicative actions from the other person, which are perceived by the observer. This forward model of social interaction is proposed to allow us to make predictions and learn about the likely behavior of another person in response to our own communicative behavior. An inverse model of action in social interaction is proposed to be used to access the hidden mental states of others, and consequently predict their behavior. The internal models of other people are considered to be decoded and learned through the mappings between our own actions and our own mental states as a priori information, thereby using our own motor system to compute the internal mental states of others, and are consequently suggested to form a basis for theory of mind.

There are crucial differences between the hypotheses of the mirror neuron system and forward models of action. Internal forward models of action are likely to be coded in the cerebellum (Wolpert et al., 1998). Consequently, neuroimaging studies have suggested that some of the characteristics of internal models of action, seen from cerebellar activity, can be extended to understanding higher-level cognitions including optimization of behavior toward long-term goals and social interaction, particularly in predicting and understanding of others' actions, theory of mind and language processing (Imamizu and Kawato, 2009). Separate mechanisms in the cerebellum may underlie different processes for switching internal models, with predictive switching being based on changes in context, and postdictive switching being based on the sensorimotor prediction error (Haruno et al., 2001). Though interestingly, activity associated with the prediction error, used for the postdictive switch, was found in the inferior parietal lobule (IPL) (Imamizu and Kawato, 2008), an area implicated in the human mirror neuron network (Chong et al., 2008).

It is evident that predictive mechanisms of simulation and inference are likely to be central to both the mirror neuron system and social forward models of action, and may underlie fundamental processes recruited in social interaction. Predictive forward models of action generated from efference copies also may provide the basis for being able to dissociate ourselves from others, on different levels of processing and in different sensory and cognitive modalities. Novel comparisons can be established if forward models of action and the mirror neuron hypothesis are framed in a predictive coding scheme, and consequently stimulating more dialog between the mirror neuron work and work on forward models, while also having implications for social cognition. A crucial issue in making such comparisons is the degree to which neural activity associated with simulated/imagined actions or forward models of planned actions constitutes the same activity as that seen during the execution of a motor action.

\section{PREPARING, PREDICTING, AND IMAGINING ACTIONS}

The dynamic changes in neural activity during preparation, online control, and imagination of one's own movements are likely to correspond with, and be embedded in, the neural processes recruited in the prediction of action kinematics and action understanding, during observation of others during social interaction (Grezes and Decety, 2001). One crucial and unresolved issue when discussing the role of prediction in social cognition and motor actions is to what degree preparatory, imagined, predictive, and observational motor responses overlap in terms of neural activity and cognitive function. For example, it may be the case that preparing for an action recruits a forward model, and therefore, the associated neural activity could in part reflect the generation of the forward model and the corollary discharge. It is also not clear as to whether imagined actions also recruit a forward model, but without the matching process of incoming sensory feedback, which could also apply to the observation of others' actions in social interaction. To further clarify the role for motor-related neural activity in social interaction and social cognition, these issues need to be first resolved.

An ERP that has been found to be associated with motor preparation is the contingent negative variation (CNV) (Walter et al., 1964). The CNV partly overlaps with the lateralized readiness potential (LRP), another similar motor preparatory response. Kilner et al. (2004) have found that a CNV is also evoked for observed actions, reflecting a preparatory or predictive response to others' actions. The LRP is thought to reflect choice response (Coles, 1989), whereby lateralized motor cortex activity is seen according to the hand used for response, before the response is made. The LRP could be another ERP to use for future explorations of how these preparatory motor responses interact with social cognitions and social contexts, such as tasksharing and action co-representation (Hollander et al., 2011). If forward models are involved in motor preparation, then such ERPs most likely reflect the neural processing of the efference copy or corollary discharge for both one's own and for others' actions.

It is quite possible that the neural activity seen in preparatory motor responses substantially overlaps with the neural activity 
during the prediction of one's own and of others' forthcoming actions. Predictable stimuli lead to faster reaction times, for which the temporoparietal junction (TPJ) has been implicated in terms of predictive motor coding (Jakobs et al., 2009), an area also crucial to the mentalizing network. Prediction and simulation of an observed action in real-time is most relevant to everyday action observation and action understanding in social interaction. Graf et al. (2007) showed subjects actions where part of the movement sequence was occluded, demonstrating better predictive performance when the timing of the occluder duration fit with the predicted movement, therefore suggesting that predictive mechanisms involved in the observation of others' actions uses real-time simulations. An intriguing study from Miles et al. (2010) found that mental time-travel, i.e., imagining the past and the future, correlated with the direction of subjects' movements, with subjects swaying forward when thinking about the future and swaying backwards when thinking of the past, suggesting an embodied representation of time and space. Interestingly, Mitchell (2009) highlights overlapping brain areas responsible for mental state inference and remembering the past, imagining the future, and spatial navigation to argue that internal self-projections are central to theory of mind processes.

The difference between the underlying neural processing involved in imagining and observing actions has relevance to the ideomotor theory of action. Recently, numerous confirmations of ideomotor principles have been revealed with neuroimaging techniques, particularly with studies demonstrating motor cortex activation for imagined actions (e.g., Decety, 1996). The ideomotor principle has also been used to explain imitation in an attempt to overcome the correspondence problem of imitation, in that movement specifics are not directly observable by the observer, and therefore, there is no direct way to match sensory input of another's actions onto our own sensorimotor system (Iacoboni, 2009; Massen and Prinz, 2009). Imagined actions and events have also been found to influence self-monitoring (De Lange et al., 2007; Turner et al., 2008), inferring a possible role in self-referential processing and consequently also in dissociating between self and other. An intriguing fMRI study has revealed that the prediction of sequential patterns can evoke activity in areas of the premotor cortex that are related to motor properties of the context of the prediction (Schubotz and von Cramon, 2002), without the execution of an action. This suggests that there may be a somatotopic mapping during the prediction of upcoming sequential events on corresponding motor cortex. The specificity of neural activity and dynamic changes involved in action execution, observation, and imagination are yet to be fully clarified. Paradigms investigating neural activity and behavior in more ecologically-valid social interactive scenarios, such as those using cooperative actions, are likely to shed more light on these questions.

\section{PREDICTING AND MOVING TOGETHER}

Studies investigating coordinated and cooperative actions are particularly relevant to social interaction and everyday social scenarios, in addition to passively observing actions. Joint action can be defined as a social interaction whereby two people coordinate their actions, often with a shared goal in mind (Sebanz et al., 2006), in other words, a co-representation of the action and its goal (Wenke et al., 2011). Given the implied role of the mirror system in imitation, co-representation, and coordinated actions, similar predictive mechanisms of prediction and simulation recruited during action observation in the mirror system could also be extended to apply to joint action, imitative, and synchronous behavior.

Imitation and synchronization of action with another person may reflect preparatory or anticipatory offline mechanisms during action observation and online real-time prediction of action (Konvalinka et al., 2010). Both may rely on similar processes of motor simulation in the brain that directly relate to inferential and predictive processes, in terms of prediction of forthcoming action and forward models of action, whereby an internal representation may guide imitation and synchronization facilitating matching of the other's actions. Individual differences in the ability to make temporal predictions for forthcoming events have been found during interpersonal sensorimotor synchronization (Pecenka and Keller, 2011), suggesting that temporal predictions could be trained through observation (Scully and Newell, 1985), and are also a necessary precursor to causal predictions, and action-effect contingencies. Therefore, the ability to make temporal action predictions may also be directly related to the ability to make more high-level, non-motor causal associations, inferences, and interpretations in social scenarios, such as during the process of mentalizing.

Automatic imitation and mimicry are thought to reflect underlying shared neural representations of action and mirror system related activity (Brass and Heyes, 2005). Imitative performance can be modulated by the social context of the action such as whether the performer is a human or not, the degree to which the observer relates to the performer of the action (Kühn et al., 2011), the level of self-focus (Spengler et al., 2010), the strategic context (Cook and Bird, 2011) and social attitudes (Cook and Bird, 2011). Synchronized movement promotes cooperative behavior (Wiltermuth and Heath, 2009) and the degree to which we perceive others as similar to ourselves (Valdesolo and Desteno, 2011) and the ability to pursue mutual goals together (Valdesolo et al., 2010), thereby also likely encouraging social cohesion. Joint action and interpersonal synchrony can also be influenced by social context, including perceived group membership (Chartrand and Bargh, 1999; Miles et al., 2011). Muller et al. (2011) found that ethnically white participants only showed a joint compatibility effect when observing a white hand, but not for a black hand, though this was eliminated when subjects were asked to take the perspective of the performer. Differences in group relations were also found to influence the tendency to co-represent remembered items of the co-actor (He et al., 2011). In addition to this, Humphreys and Bedford (2011) used neurological patients to infer that theory of mind and joint action may have some common neural substrate.

It is clear that much work has already been done to investigate the interdependency between high-level social cognitive processing and low-level motor processes. The top-down influence of social information on bottom-up neural motor activity and the apparent embededness of social cognitive processing in the processing of both one's own and others' motor actions demonstrates 
the potential coupling of movement to social cognition. It is also evident that predictive mechanisms of simulation and inference, and predictive coding frameworks, provide a fruitful foundation on which to build further common dialogs between currently disparate research disciplines and theoretical viewpoints. However, it is not only the motor response associated with the observation of others' actions that is represented in the observer's brain, but also includes the consequence of the outcome and the implications of the observed action in terms of error, feedback, and reward, and therefore consequently influencing decision-making and learning. Predictive mechanisms also lie at the core of the processes of evaluation of the outcomes of others' actions, and can be applied to both non-social and social contexts.

\section{COGNITIVE CONTROL AND ERROR MONITORING IN A SOCIAL CONTEXT}

The ability to accurately detect and process errors is crucial for learning. Certain EEG ERPs are thought to be indices of errorprocessing and the reward prediction error. The feedback-related negativity (FRN) is evoked when negative or positive feedback is given following response choice and is considered to be an index of reward prediction and expectancy violation (Holroyd and Coles, 2002). An error-related negativity (ERN) is seen following the onset of muscle activation during an erroneous response in a forced choice reaction time task (Falkenstein et al., 1990). The ERN is an index of error-processing and response monitoring, when the intended response is different from the executed response (Baker and Holroyd, 2011), and has been found to originate from the anterior cingulate cortex (ACC) (Dehaene et al., 1994). Both the ERN and FRN are intrinsically linked to each other and are mediated by the mesencephalic dopamine system and projections to the ACC (Holroyd and Coles, 2002).

Some studies have recently shown that corresponding brain activity involved in error and feedback processing can also be evoked by the observation of others' performance. An ERN and FRN is evoked when watching other people's mistakes (observational ERN or oERN) (Van Schie et al., 2004) and when observing feedback from other people's response choices (observational FRN or oFRN), respectively, with the oERN and oFRN both also thought to originate from the ACC (Yu and Zhou, 2006). Shane et al. (2008) have confirmed the activation in the ACC, in the dorsal region, during one's own and observation of a confederate's errors, with additional activity also being found in orbitofrontal areas and premotor cortex. Though, interestingly, a dedicated network appears to be active only when observing others' errors, which includes the inferior parietal cortex (IPC) and the rostral and ventral parts of the ACC (r/vACC), with the IPC correlating with measures of perspective-taking and the r/vACC correlating with self-reported empathetic concern (Shane et al., 2008, 2009). Another recent study found activity in the MPFC, an area associated with the mentalizing network, specifically activated for errors that affected others (Radke et al., 2011).

Observational error and feedback processing also seems to be influenced by the degree of self-relatedness and the interpersonal relationship between the observer and the performer, i.e., if the performer is a friend or a stranger, with differences seen in activity in error-related brain areas (Newman-Norlund et al., 2009), and in error-related (Carp et al., 2009) and feedback-related ERPs
(Kang et al., 2010; Ma et al., 2011). Competition and cooperation appear to modulate processing of observed errors to the degree that they influence performance monitoring and even modify performance adjustments. For example, when observing someone else's errors, it appears that a post-error slowing occurs for one's own errors in a cooperative scenario, although there is a post-error speeding in the competitive scenario (De Bruijn et al., 2012; Nunez Castellar et al., 2011). An ERN has also been found to be evoked by observed errors performed by cooperators, whereas observed correct responses of competitors evoked a later ERN (Koban et al., 2010). It has been confirmed that this activity is likely to be not just associated with self-reward, but is a reflection of performance monitoring and updating of expected outcomes based on others' actions (De Bruijn et al., 2009). The FRN and oFRN have also been shown to be modulated by competition and cooperation (Itagaki and Katayama, 2008; Rigoni et al., 2010; Van Meel and Van Heijningen, 2010), suggesting that this neural response is influenced by both the benefit or loss to oneself, and the benefit or loss of others (Marco-Pallares et al., 2010).

These studies all demonstrate how the neural processing of both one's own and others' errors and feedback can be directly influenced by social context and by differences in the social relationships between confederates involved in a social scenario. Therefore, the central role of error and feedback in predictive mechanisms of inference and learning provides a fundamental link between prediction and social cognition. However, an important note to make here is that it is not clear as to how others' gains interact with our own processing and valuation of reward, i.e., from the observed choices of others. This is a crucial issue, as it addresses the degree to which others' gains can be rewarding for us. Differences in neural activity may be wholly reflecting some form of "empathetic" response to others' experience, or, though not mutually exclusive, may be an index of the relevance of the reward to oneself, as the outcome of others' choices may be indirectly associated with a reward for us.

\section{SOCIAL LEARNING AND SOCIAL REWARDS}

Observational learning is acquired through making associations between actions and their outcomes, and the value associated with that action and the predicted outcome. It is becoming more apparent that there are some common cognitive and neural processes driving both active experiential learning and observational social learning. In particular, social learning has been proposed to be based on the same simple processes recruited in associative learning. Heyes (2011) compares learning across different species suggesting that learning only becomes social through adaptation to interactions with conspecifics, and "tuning in" of perceptual, attentional, and motivational information channels to other social agents. She convincingly argues that social learning does not involve mechanisms that are different from those used in non-social learning, and therefore do not have special "social" properties. In support of this, Jones et al. (2011) found neural activity in areas associated with basic reinforcement learning during a task involving acceptance from peers. One fMRI study also revealed similar underlying neural mechanisms during social valuation and non-social associative reward-based learning, finding a "social prediction error" (Behrens et al., 2008). Computational 
modeling has also been used to relate the brain network responsible for reward-related processing with the theory of mind network (Behrens et al., 2009). Therefore, the principles underlying associative learning can also be extrapolated to explore the role of predictive mechanisms in observational social learning.

It is already known that the processing of reward is dependent on the context in which the reward is presented (Nieuwenhuis et al., 2005). Although, there is much evidence to suggest that there is something special about social contexts (e.g., cooperation versus competition) and social relations (e.g., ingroup versus outgroup) that modulate the computation of value. Differences in activity can be seen in brain areas associated with motivated behavior and reward evaluation when a social betting task is compared to non-social betting (Nawa et al., 2008), namely the amygdala, the right DLPFC and the ventral striatum. The processing of feedback and one's own experience of reward, for others' gains or losses interacts with how the observer views the other person, in terms of the opinion or social evaluation of them. Our own valuation of objects can be influenced by others' opinions, as Campbell-Meiklejohn et al. (2010) demonstrated differences in activity in the ventral striatum, an area thought to code prediction error-related activity, depending upon the opinion of an "expert" reviewer. Ratings of subjective value and the associated neural activity have also been shown to be affected by the valuations made by one's peers, particularly in the nucleus accumbens and the orbitofrontal cortex (OFC) (Zaki et al., 2011). In addition, the dorsal striatum has been found to encode reward prediction errors in both one's own experiential instrumental conditioning and the observation of others' (Cooper et al., 2012). There is some evidence to suggest that there may be a common underlying neural network related to one's own valuation of rewards and the valuation of others' action outcomes during observational learning, which may culminate in the ventromedial prefrontal cortex (VMPFC) (Behrens et al., 2008; Hare et al., 2010). A review of social preferences collates numerous fMRI studies to find common activation in the dorsal and ventral striatum for the processing of social rewards, with these areas substantially overlapping with areas related to reinforcement learning and anticipation of monetary reward (Fehr and Camerer, 2007), further adding to the argument for shared neural representations for one's own and others' rewards.

Sescousse et al. (2010) found prediction error-related activity in the ventral striatum, anterior insula, and the ACC for monetary reward, and from the presentation of erotic stimuli, suggesting some common coding of prediction errors regardless of the type of reward, social or not. However, a more recent study found distinctions between brain areas activated during the processing of financial reward feedback, and the valuation of social stimuli, suggesting some separability between the brain's classical reward circuit and the network responsible for the valuation of social stimuli (Evans et al., 2011). Furthermore, a distinction between action prediction errors and outcome prediction errors have been made in neural areas associated with observational learning (Burke et al., 2010). The action prediction error is proposed to reflect the discrepancy between expected and observed action choices, coded in the DLPFC, and the outcome prediction error is thought to represent the discrepancy between the expected and observed outcome received by others, coded in the VMPFC.

In social learning, it may be the case that social context and our opinion of others induces different motivational states that correspond to different utility functions, in terms of reinforcement learning theory and expected utility theory, which consequently dictate social decisions and future social judgments. The motivational states in learning theory (Niv et al., 2006) are mappings of the utility onto the outcome, whereby valuation is driven by both external factors (i.e., the probability of the occurrence) and the internal context (the motivational, emotional, and cognitive state). This could be paralleled in social contexts in which the internal state is driven by predetermined judgments and opinions of the other person and our intrinsic social needs (the internal context), that is weighed up against a statistical probability calculation based on prior experience, learned through socially relevant stimuli and cues (the external factor).

There is conflicting evidence to argue for and against a distinction between social observational and non-social/active learning. However, it appears that more weight is given to the side that proposes a lack of distinction, in that both largely share some common neural substrates, with both also utilizing a form of prediction error, associated with both the valuation of one's own and of others' outcomes in non-social and social scenarios, respectively. Although it is clear that social learning involves an additional dimension in which the social context can directly influence the valuation of an outcome. The social context created by the external environmental situation (e.g., competition or cooperation) or by internal motivational states (including that created from prejudice or through the social relationship with a confederate) can determine the valuation of rewards from others' outcomes. Consequently, social contextual factors will contribute to the formation of social judgments and as a result could also drive decision-making in social situations.

\section{SOCIAL DECISION-MAKING AND ECONOMIC GAMES}

Social decision-making deals with high-level computations based on complex socially relevant information such as fairness, trust, social norms, and social preference. Economic decision-making in social contexts, though apparently recruiting additional processes, is still rooted in reward processing and cognitive control, and can also be framed in terms of probabilistic predictive computations, and consequently has been shown to involve similar neural structures in both social and non-social decision-making. This has been largely explored with economic games that include a social component, often with some form of social interaction.

Feedback indicating a violation of a social norm and social expectation has been shown to evoke an FRN, suggesting that the brain treats social deviance in a similar way to a prediction error (Harris and Fiske, 2010; Kim et al., 2011). Klucharev et al. (2009) also confirmed this with activity seen in the ACC and supplementary motor area when there is conflict with a social norm. It is likely that cooperative behavior and biding by social norms is based on observational learning and inference-based processes (Boyd and Richerson, 1988; Seymour et al., 2009; Yoshida et al., 2010). These findings relate closely to studies showing the effect of others' opinions on our own valuation of objects, as previously 
mentioned. Popularity ratings have been shown to influence the valuation of adolescents' ratings of music, and interestingly, the tendency to change one's opinion of a song positively correlated with activity in the anterior insula and the ACC (Berns et al., 2010). Activity in the DLPFC and ACC, both crucially involved in cognitive control and error processing, have consistently been found to be activated when making moral decisions, in particular, when making decisions between fair and unfair offers (Sanfey et al., 2003; Greene et al., 2004). A study using a social comparison scenario that induced self-reported envy found that activity in the dorsal ACC was positively correlated with levels of envy (Takahashi et al., 2009). The ACC and DLPFC have also been shown to be activated when one breaks a promise, as compared to fulfilling that promise (Baumgartner et al., 2009).

The overlap between reward prediction error-related neural activity and activity utilized in social judgments implies an underlying role of prediction in more complex, higher-level socially relevant psychological processes, such as empathy, trust, judgments of fairness, envy, shame, and guilt. Activity in the ventral striatum has been found during the experience of mutual human cooperation, as opposed to cooperating with a computer (Rilling et al., 2002, 2004), with two other reward-related areas implicated in reciprocated cooperation, namely the caudate nucleus (Rilling et al., 2002, 2004; Delgado et al., 2005) and the OFC (Rilling et al., 2002, 2004). It is likely that people experience some hedonic pleasure when acting altruistically (Thibaut and Kelley, 1959), which outweighs the potential financial cost. This is confirmed in studies showing activity in the reward circuit when giving charitable donations (Moll et al., 2005; Harbaugh et al., 2007). A proposed computational model of decision-making demonstrates that the application of reinforcement learning theory in game-theoretic social interactions and imitative or inference based observational learning can be used to generate altruistic behavior (Seymour et al., 2009). The evaluation of fairness and the social comparison of monetary rewards have been associated with activity in the ventral striatum (Fliessbach et al., 2007), with fairer offers also inducing greater activation in the VMPFC and higher subjective ratings of happiness (Tabibnia et al., 2008). The VMPFC has also been found to be implicated in judgments of trust (Krajbich et al., 2009) and being trusted by others (Li et al., 2009). The DMPFC, caudate nucleus, and the striatum have been shown to be activated when learning the trustworthiness of another person (King-Casas et al., 2005). Findings of activity in the VMPFC, medial OFC, and DLPFC in emotional synchrony of another person also relate to this (Kühn et al., 2011). Implicit judgments of trustworthiness from facial cues influence social decision-making (Van 'T Wout and Sanfey, 2008; Schlicht et al., 2010), and the use of reinforcement learning models of trustworthiness also suggests that the evaluation of trust is based on probabilistic beliefs that are dynamically updated according to the proceeding experience and prediction error (Chang et al., 2010).

The substantial overlap between areas encoding prediction errors, error monitoring, and those implicated in social decisionmaking tasks implies a common neural basis for social and nonsocial decision-making processes. This therefore, also highlights the central role of predictive mechanisms of inference in social decision-making and the formation of complex social judgments.
In addition to shared neural representations of others' motor actions, outcomes of others' actions, and the implications of others' actions on the observer, there can also be shared sensory and emotional experiences when watching others. This then brings us closer to a conceptualization of empathy in which we not only experience the cold cognitive processes of others, but also experience others' emotional state during observation.

\section{PREDICTING OTHERS' FEELINGS}

An interesting study has recently shown synchronized arousal, reflected in heart rate data, among spectators and fire-walkers during observation of a collective ritual (Konvalinka et al., 2011). Just as sensorimotor matching or motor resonance can occur during action observation, it appears that other people's sensations and emotions can also be contagious and therefore, has consequently been linked with the mirror system. A recent fMRI meta-analysis of areas implicated in the human mirror system found significant overlap with areas involved in emotional processing (Molenberghs et al., 2012). Observed tactile stimulation can induce shared experiential and neural representations of the others' somatosensation, including another's pain. Threat detection is involved in evaluations of trustworthiness and social decision-making. This clearly has adaptive advantages for survival and has evolved from the ability to efficiently perceive fear-related stimuli, and can also be transmitted through social interaction. Fear-conditioning is likely to be based on similar predictive mechanisms as in reinforcement and associative learning, and these principles could legitimately be extended to explain the social transmission of fear by observational learning processes. Emotional contagion forms the basis for affective empathetic responses (Decety and Ickes, 2009), which may be founded on internal predictive or anticipatory emotional representations (Gilbert and Wilson, 2007). Simulations of emotions, or "pre-feelings," may not only be used to imagine future emotional states, but may also be used to simulate others' emotional states in social interactive scenarios.

Observing actions, tactile, and painful stimulation in others all invoke activity in the brain of the observer in secondary somatosensory cortex (SII) and BA2 (Brodmann Area 2-posterior primary somatosensory cortex), which is adjacent to SII (Keysers et al., 2010). Some authors have pointed out a lack of distinction between motor and somatosensory activation during the observation of others' actions, and consequently argue for a lack of distinction between somatosensation and motor processes in the hypothesized mirror neuron system (De Vignemont and Haggard, 2008). Numerous fMRI studies have confirmed this overlap showing activation of SII, but more significant activation of BA2 during action observation (Grezes et al., 2003; Dinstein et al., 2007; Gazzola et al., 2007; Gazzola and Keysers, 2009; Turella et al., 2009). Empathy and self-versusother-related processing can also influence somatosensory perception (Jackson et al., 2006; Lawrence et al., 2006). Serino et al. (2009) found that tactile somatosensation on one's own face, while observing another person's face being touched, was enhanced when the observed face was of the same ethnic or political group. Serino et al. (2008) also previously discovered that viewing one's own face can enhance tactile sensitivity, which is 
also reflected by enhanced neural activity in a ventral parietal area in a later fMRI study (Cardini et al., 2011). This also appears to work in the other causal direction, in which somatosensory stimulation of one's own face can improve self-face recognition (Tsakiris, 2008).

The prediction error signal has a crucial role in fearconditioning and avoidance behavior, achieved by learning relationships between harmful events and environmental stimuli (Delgado et al., 2008; McNally et al., 2011; Spoormaker et al., 2011). Many different animals can evidently learn fear from the observed fear-related behaviors of a conspecific (e.g., John et al., 1968; Kavaliers et al., 2001; Munksgaard et al., 2001; Knapska et al., 2010). Aversive learning can be communicated by primates through fearful face expressions, with some studies providing support for the suggestion of common processes in fear conditioning and observational fear learning (Mineka et al., 1984; Mineka and Cook, 1993). Facial expressions are also one of the main ways for socially transmitting fear in humans, with the expression of another's response to stimuli serving as the Pavlovian aversive US (unconditioned stimulus) for the observer (Gerull and Rapee, 2002). Other physical cues can also lead to learned fear responses through observation (Berber, 1962), and even just abstracted information about a fearful response can lead to social transmission of fear (Hygge and Ohman, 1978), though this is also determined by context (Lanzetta and Englis, 1989; Singer et al., 2006). Neuroimaging studies reveal similar networks involved in both fear conditioning and observational fear learning. Primarily, the amygdala is central to the processing of fear, from both one's own experience and from others', though additional areas have been implicated exclusively in observational fear learning, including the anterior insula and ACC, possibly reflecting anticipation, and parts of the MPFC likely to be involved in some mental state inferential processing of the observed person (Olsson et al., 2007).

Fear and pain are directly related to one another, and in a social context, observing someone else's pain can induce a representation of that pain in the observer, with activations seen in the observer's somatosensory cortex (Cheng et al., 2008). Observation of others' pain is also directly related to the social transmission of fear. Neural responses induced by empathy for others' pain have also been shown to be modulated by perceived fairness (Singer et al., 2006), group membership (Forgiarini et al., 2011), emotional closeness (Beeney et al., 2011), emotional context (Han et al., 2009), self-relatedness (Perry et al., 2010), the identity of the person being observed and personality differences of the observer (Mazzola et al., 2010; Goubert et al., 2011). Goubert et al. (2011) have presented an intriguing account of the observation of pain and pain-related fear from an observational learning perspective, with added recent experimental evidence (Helsen et al., 2011). In support of this, Meulders et al. (2011) have demonstrated that pain-relevant fear conditioning is driven by associative learning mechanisms. It may also be the case that learned aversive behavior is directly linked to reward processing, in that it has been shown to be modulated by monetary reward (Guo et al., 2011), and the avoidance of aversive outcomes may in itself be rewarding, and therefore reinforcing aversion avoiding behavior (Kim et al., 2006).
In sum, it is evident that anticipatory neural responses, and predictive coding in the context of learning, are crucial to empathetic somatosensory representations of others' experiences and consequently have a central role in observational learning of fear and pain and emotional contagion. The learning of aversive behavior, transmitted socially by others, will have substantial mediating effects on social decision-making and social behavior. Both fundamental predictive inferential mechanisms and high-level expectations are likely to be at the root of such processes, with interaction and interdependence between processing levels forming the basis for fear-related social decision-making. Predictive mechanisms of simulation and inference are likely to form the underlying processes that allow us to have empathy for others' pain and to learn about aversive stimuli through observation. The ultimate function of shared representations of others' actions, errors, rewards, sensations, and emotions is likely to be the basis for understanding others' minds in social interaction. Arguably, at the highest level of understanding others' minds is the ability to make inferences about others' mental states, which may be founded upon many of the principles already discussed.

\section{PREDICTING OTHERS' MINDS}

In social neuroscience, "mentalizing" or "theory of mind" refers to the ability to infer the mental states of others, ultimately to predict another person's behaviors, and is a central topic of discussion. Daunizeau et al. (2010) present a meta-Bayesian model for solving the Inverse Bayesian Decision Theory problem, which is the problem of inferring the hidden causes of sensory signals under a prior assumption about the causes. These signals are hidden both in our own experience of sensory input and also hidden from the observer when observing others' behavior, as we do not have perceptual access to these sensory signals. When observing others, the problem is that we are required to determine someone else's prior beliefs and goals with only their behavior as the information available to infer this. This meta-Bayesian solution has been suggested to explain processes such as metacognition, mental state inference, and theory of mind. A recent predictive model of theory of mind has been proposed by Baker et al. (2011), which relies on Bayesian inferential statistics to model belief and goal-dependent action, which is mediated by the state of the environment and perceptual access to the belief state, and by general knowledge of the world and by general preferences. Bayes' rule is used to model mental state inference, in which action understanding is acquired from integrating "bottom-up information from observed actions and top-down constraints from the prior to infer the goal, given observed actions and the environment." This inverse planning model is described to account for goal-based predictions of future actions in new situations, according to predictions formed from similar previous experiences. Comparable to this, the mental state inference model (MSI), another computational model of mental state inference, uses forward models of action in a prediction circuit to incorporate visual feedback as the control mechanism for inferring the goals and intentions of others through mental simulation or motor imagery (Oztop et al., 2005). Mental state inference and theory of mind may represent, and be achieved by, the culmination of many fundamental predictive inferential, and simulation processes related to the processing 
of others' actions, errors, rewards, and emotional cues. It is also evident that the models of mental state inference that incorporate some predictive principles, such as Bayesian inferential statistics and forward models of action, can accurately simulate behavior.

\section{DISCUSSION \\ SUMMARY}

In the present article, we sought to review findings from a huge body of literature on the role of prediction in perception, action, and learning. Specifically, our aim was to highlight the relevance of prediction in the realm of social neuroscience. Accordingly, prediction, in its many forms, plays a central and fundamental role in social cognition. In light of the interaction and interdependence of predictive processes at different levels of processing and inference, such processes are best represented by hierarchical models of the brain, as this also reflects the hierarchical structure of the cortex, with top-down predictions being conveyed through backward connections, and prediction errors being propagated forward across the cortical hierarchy. Previous experience shapes and guides our current behavior and the choices we make. Predictive coding models that include generative forward models and Bayesian statistical inference present a plausible mechanistic platform to integrate a broad range of topics. Adaptive social behaviors and social learning relies on updating states based on prediction errors. Experience-dependent development of sensorimotor coupling may be crucial to the development of the sensorimotor representation of the embodied self and a sense of agency. Among these, this article draws numerous parallels between fundamental principles of cognition, previously thought to be non-social, with cognitive processes required for social interaction.

Three main points are proposed in our review that link predictive mechanisms in the brain to processes encompassed in social cognition. The first point is that both bottom-up sensory input and top-down expectancies for non-social cognitive processes, founded upon predictive principles of inference and simulation, are responsible for social cognitive processes, and are essential for the processing of social information. It is suggested that the development of such non-social predictive mechanisms are crucial in the development of socially relevant neural and psychological processes. Secondly, but not unrelated to the first point, this review highlights a number of studies which imply that there may not be a categorical difference between related social and non-social cognitive processes, particularly also in terms of the neural substrates of such processes. The similarities between neural activity recruited for our own experiences and during the observation of others' appear to outweigh the differences. Thirdly, it is clear that the framing of stimuli in a social context can have a modulatory influence on non-social predictive neural activity and behavioral processes. Social contextual information evidently has a substantial additive contribution to top-down modulations of bottom-up sensory input. Generative forward models of perception and action may integrate social information to facilitate mental state inference and understanding of others' actions and intentions. It is also legitimate to propose the existence of "social" forward models that compete against each other, with other nonsocial forward models and with bottom-up sensory input. It is also evident that there is a bidirectional relationship between social information and sensory processing, i.e., both a forward and inverse relationship.

\section{COMPETING "SOCIAL" INTERNAL MODELS}

Multiple bottom-up and top-down predictive systems are likely to be at play in the brain, working together, and competing against one another in different levels of processing, being both hierarchical and parallel in nature. Evidence for this can be seen in the induction of interference in action-perception coupling (e.g., Zwickel et al., 2010a,b), whereby predictive systems compete with each other. Anscombe (1957) states that there an almost infinite number of possible inferential descriptions of a single action. Comparatively, there are also an infinite number of inferential interpretations of social cues, socially relevant stimuli, and social scenarios. There may be internal "social" models that compete with other top-down internal models, and bottom-up sensory information, consequently causing the modulatory effect of social information and social context on action, perception, learning, and other cognitive processes. These generative "social" internal models would be acquired through previous social experience and social knowledge. This suggestion of competing social predictive systems working in synchrony is supported by the MOSAIC model for sensorimotor control and social interaction (Wolpert et al., 2003), which proposes distributed cooperation and competition of internal models whereby forward and inverse models compete for overall control. Competition between predictive systems is also likely at different levels of information processing, whereby bottom-up prediction in terms of perception and action compete with likelihood estimations and top-down prior beliefs (i.e., knowledge established from social experience) in addition to the top-down priors proposed in current Bayesian predictive models of perception and action. Top-down modulations of prediction in social contexts are likely to be multidimensional, including both cognitive and affective dimensions. Evidence of competing predictive systems from the modulation of sensorimotor control and action planning by social information (Ferri et al., 2011; Sartori et al., 2009a,b) and emotional context is clearly illustrated with numerous studies mentioned in this review.

\section{SOCIAL PREDICTION ERRORS}

A category of social prediction errors are likely to be present in social learning, social action and interaction, and social expectancy violations, reflecting the discrepancy between expectation and actual experience in social situations. These subsequently may be founded upon similar cognitive processes and neural substrates as prediction errors coded in non-social contexts. The difference between a social and non-social prediction error would be that the social prediction error is mediated by additional modulating factors, including social knowledge and expectations of others' behavior. For example the coding of the social reward prediction error, when observing the outcomes of others' choices, may produce a prediction error similar to that produced when one observes the outcome of one's own choice, but rather the value becomes relative to the effect of the observed outcome on the observer, i.e., how rewarding other's rewards are to the observer. As already mentioned, this can be modulated by 
cooperation and competition, and by the relationship between the observer and the performer. A social action prediction error could be generated when predicting, simulating, or inferring others' actions in a social interaction, as described by the MOSAIC model of social interaction (Wolpert et al., 2003). Another category of prediction error that may be specific to social interaction could be a higher-level complex prediction error that is founded upon previously learnt social information whereby expectancies about others' social behavior are formed. This could be produced in circumstances such as when social norms are violated or when promises are broken. Expectations, or predictions, for this specific social behavior prediction error could come from cultural knowledge, or may be created by contextual information. Contextual information for social expectancies could come externally from environmental cues, and particularly the context of the social situation, or could be generated from internal cues such as an individual's affective state, or from a cognitive bias, such as an attributional bias.

\section{THE "PREDICTIVE" BRAIN AS A FOUNDATION FOR THE "SOCIAL" BRAIN}

Due to the coupling of action, perception, and learning, it may not be valid to consider these domains as separable or independent, and consequently predictive coding models dealing with these domains may overlap to the degree unto which they also operate under some common processes. This may also be the case for socially relevant cognitions in that the fundamentals of perception and action are embedded in processes considered to be specially "social," but instead could be structural and functional extrapolations of these fundamental principles that link action, perception, and learning, i.e., fundamental predictive mechanisms. Therefore, it also follows that it is improbable that distinct neural structures or networks can be found as responsible for predictive mechanisms, which may also parallel the ubiquity and omnipresence of the "social brain" and the neural correlates of social cognition and social interaction. As evident from many of the studies mentioned in this article, there is substantial overlap between the "predictive" brain (see Bubic et al., 2010) and the "social" brain (e.g., Abu-Akel and Shamay-Tsoory, 2011), including areas such as the DLPFC, MPFC, DMPFC, ACC, TPJ, OFC, medial temporal areas, precuneus, ventral striatum, amygdala, lateral parietal areas and the motor, premotor and somatosensory cortices.

The modulation of predictive sensory, motor and learning processes, and associated neural activity by social information, could be explained merely by an enhanced attentional orientation toward stimuli that have saliency created by the social relevance. Social information may not be of a categorically different type, as compared to non-social information, but instead could just have a higher level of priority in terms of information processing in the brain, and therefore be more pronounced in terms of saliency, and consequently capturing attention and utilizing greater cognitive resources. This would be in line with work on social cue orienting; findings of automatic attentional orientation to social cues (Driver et al., 1999), gaze cues and joint attention (Friesen and Kingstone, 1998). Tipper et al. (2008) found little difference between brain areas activated with social cues and non-social cues, though this is also contrasted by other conflicting studies (Greene et al., 2009). Prioritizing the processing of social information over non-social information, in terms of attentional orientation and cognitive resources, may have had some adaptive evolutionary benefits for survival and reproductive success.

\section{EVOLUTION OF THE "PREDICTIVE" AND THE "SOCIAL" BRAIN}

The ability to accurately predict future events is always a major challenge for all living creatures, particularly because a failure to learn from errors may have fatal consequences. This suggests that natural selection has strongly operated on predictive mechanisms, however, in very different ways. Hibernators, for example, can "predict" future food shortages, even if they have never experienced such a situation before. In other words, their predictive knowledge is innate. In the case of our own species, future scenarios are much more diverse, and therefore, even more unpredictable. Consequently, prediction mechanisms need to be more flexible, are more dependent on feedback (to adjust goalsetting), and are perhaps more independent on actual sensory input. For example, humans readily learn that there may be a food shortage in the future, independent of the current food supply. In addition, the complexity of social encounters in ancestral and contemporary societies has shaped predictive mechanisms to become more sophisticated in social matters. Successfully predicting the behavior of conspecifics has almost certainly paid-off reproductively.

From an evolutionary point of view, it is conceivable that predicting and anticipating the sources of potential threat, but also the availability of food resources, is largely independent of specific "social" contexts. Arguably, however, in primates and humans, the increasing complexity of social environments may have left its mark on how predictive mechanisms operate in the brain. Put another way, predictive mechanisms have been constantly shaped by environmental contingencies that, in the case of primates, consequently became more social, and less non-social. Living in complex social groups or troops certainly poses different demands on predictive mechanisms compared to living a solitary life. For example, while social group living provides protection from predation, it also increases intersexual competition for mates. Consistent with this assumption, Sallet et al. (2011) have shown that social network size and social status in Macaques was correlated with gray matter volume in the superior temporal cortex and rostral prefrontal cortex and with increased connectivity between frontal and temporal areas, suggesting that the size of the social group an individual is able to cope with impacts on both brain structure and function (Sallet et al., 2011). Arguably it should also be advantageous to be able to correctly predict the behavior of conspecifics. Therefore, individuals who have been better in predicting others' behavior may have been those whose genes benefitted from a greater reproductive success. If correct, this strongly suggests that selection pressures operating on predictive mechanisms have made them more malleable by social matters. A hypothesis derived from these considerations would be that the brain areas concerned with "social" prediction are similarly moulded by the complexity of the social environment (i.e., network size). 


\section{WHEN THE "PREDICTIVE" BRAIN GOES WRONG}

The relationship between predictive mechanisms in cognition and the brain, and social cognition also has implications in psychopathology. If the development of predictive mechanisms have evolved with increasing complexity, with the adaptation of social cognitions as a result of this, then it is also probable that deficits of social cognition (such as theory of mind, empathy, imitation, self-recognition) are manifested by underlying disturbances in the "predictive brain" in pathologies like psychopathy (Hare, 1980), autism (Mundy et al., 1986), and schizophrenia (Brüne, 2005). Brazil et al. (2011) found a reduced ERN in psychopaths only when observing others' actions, when compared to non-psychopathic subjects. However, they also found a reduction in the ERP for correct responses, therefore reflecting a more general deficit in the processing of others' action outcomes in psychopathy. These findings suggests that deficits in higher level social cognitions, such as empathy, may also be related to processing of others' actions and action understanding, and would therefore be reflected in associated neural activity. This is also suggested by studies that have found abnormalities in mirrorneuron related activity in people with autism (Oberman et al., 2005) and schizophrenia (Singh et al., 2011) as indexed by EEG and the mu rhythm suppression, although conflicting results make this still unclear (Raymaekers et al., 2009). It has been suggested that psychosis may be partly caused by disturbances and dysfunctions of predictive mechanisms in different domains and in different levels of predictive processing. A deficit in fundamental predictive mechanisms of cognition may be expressed in certain psychotic symptoms, including passivity symptoms such as disturbances in sense of agency, auditory hallucinations, and delusions of control (Fletcher and Frith, 2009; Corlett et al., 2010), which are intrinsic to both social cognition and predictive mechanisms. Inherent of this may also be the abnormalities seen in error-processing in schizophrenia and the concurrent effects on learning, cognitive control, and self-monitoring (Carter et al., 2001).

\section{CONCLUSIONS AND FUTURE DIRECTIONS}

Future studies may aim to directly compare social and non-social predictive processes in the brain and in behavior to further elucidate how prediction is linked with social cognitive processes. This article encourages a number of questions, with testable hypotheses, which could be addressed by future work. Firstly it is suggested that neural structures and networks involved

\section{REFERENCES}

Abu-Akel, A., and Shamay-Tsoory, S. (2011). Neuroanatomical and neurochemical bases of theory of mind. Neuropsychologia 49, 2971-2984.

Allison, T., Puce, A., and McCarthy, G. (2000). Social perception from visual cues: role of the STS region. Trends Cogn. Sci. 4, 267-278.

Anscombe, G. E. M. (1957). Intention. Oxford: Blackwell.

Arnal, L. H., Wyart, V., and Giraud, A. L. (2011). Transitions in neural oscillations reflect prediction errors

in non-social predictive processing, such as those coding for the prediction error and the efference copy, are also essentially utilized in social decision-making, social learning, and social interaction. Meta-analyses of functional imaging studies comparing analogous social and non-social cognitive processes will give more insight into this. It is also proposed that further work be done to investigate the interaction between top-down social information and expectations, non-social top-down priors and bottom-up sensory input, and the competition between these. Behavioral experiments comparing interference between levels of social and non-social processing, and computational hierarchical models would be useful to investigate such questions. This may also reveal different degrees of prioritization of information processing according to social versus non-social categorization of information. Pathological conditions associated with impairments in social functioning may serve as appropriate models to explore the independence of social cognition from predictive processing. Fletcher and Frith (2009) present a Bayesian framework for explaining the positive symptoms of schizophrenia and the potential for dysfunctions of underlying predictive mechanisms, such as the prediction error, corollary discharge, and efference copy, being at the core of such symptoms. If distinct patterns of impairment in predictive cognitive processes exist in such psychopathologies, it can be hoped that these can be therapeutically targeted to concurrently improve social functioning, and also to reduce other pathological symptoms related to predictive processing. Social interaction requires the understanding of others' beliefs, intentions, and emotions, which are formed from our own internal representations, and predictions, of others' mental states, though it is still under debate as to where and how internal representations of other social agents are represented in the brain. The use of a predictive coding framework provides conceptual scaffolding to bridge different domains of cognition and different research disciplines. In exploring social neuroscience under the guise of prediction, a more integrated and inclusive approach is permitted to understand the brain as a whole and not just a sum of its parts.

\section{ACKNOWLEDGMENTS}

The author Elliot C. Brown would like to thank Cumhur Tas and Burak Erdeniz for their invaluable comments and inspiration for this article. The authors would also like to thank the reviewers for their helpful, constructive, and supportive comments that allowed the authors to bring more clarity and focus to the article.

by the feedback error-related negativity and N200. Biol. Psychol. 87, 25-34.

Bar, M. (2007). The proactive brain: using analogies and associations to generate predictions. Trends Cogn. Sci. 11, 280-289.

Bar, M., Aminoff, E., Mason, M., and Fenske, M. (2007). The units of thought. Hippocampus 17, 420-428.

Bar, M. (2009). The proactive brain: memory for predictions. Philos. Trans. R. Soc. Lond. B Biol. Sci. 364, 1235-1243.
Barrett, L. F., and Bar, M. (2009). See it with feeling: affective predictions during object perception. Philos. Trans. R. Soc. Lond. B Biol. Sci. 364, 1325-1334.

Barsalou, L. W. (2009). Simulation, situated conceptualization, and prediction. Philos. Trans. R. Soc. Lond. B Biol. Sci. 364, 1281-1289.

Bastiaansen, J. A., Thioux, M., and Keysers, C. (2009). Evidence for mirror systems in emotions. Philos. Trans. R. Soc. Lond. B Biol. Sci. 364, 2391-2404. 
Baumgartner, T., Heinrichs, M., Vonlanthen, A., Fischbacher, U., and Fehr, E. (2008). Oxytocin shapes the neural circuitry of trust and trust adaptation in humans. Neuron 58, 639-650.

Baumgartner, T., Fischbacher, U., Feierabend, A., Lutz, K., and Fehr, E. (2009). The neural circuitry of a broken promise. Neuron 64, 756-770.

Beeney, J. E., Franklin, R. G. Jr., Levy, K. N., and Adams, R. B. Jr. (2011). I feel your pain: emotional closeness modulates neural responses to empathically experienced rejection. Soc. Neurosci. 6, 369-376.

Behrens, T. E., Hunt, L. T., Woolrich, M. W., and Rushworth, M. F. (2008). Associative learning of social value. Nature 456, 245-249.

Behrens, T. E., Hunt, L. T., and Rushworth, M. F. (2009). The computation of social behavior. Science 324, 1160-1164.

Berber, S. M. (1962). Conditioning through vicarious instigation. Psychol. Rev. 69, 450-466.

Berns, G. S., Capra, C. M., Moore, S., and Noussair, C. (2010). Neural mechanisms of the influence of popularity on adolescent ratings of music. Neuroimage 49, 2687-2696.

Blakemore, S. J., Goodbody, S. J., and Wolpert, D. M. (1998). Predicting the consequences of our own actions: the role of sensorimotor context estimation. J. Neurosci. 18, 7511-7518.

Bortoletto, M., Mattingley, J. B., and Cunnington, R. (2011). Action intentions modulate visual processing during action perception. Neuropsychologia 49, 2097-2104.

Boyd, R., and Richerson, P. J. (1988). The evolution of reciprocity in sizable groups. J. Theor. Biol. 132, 337-356.

Brass, M., and Heyes, C. (2005). Imitation: is cognitive neuroscience solving the correspondence problem? Trends Cogn. Sci. 9, 489-495.

Brass, M., Schmitt, R. M., Spengler, S., and Gergely, G. (2007). Investigating action understanding: inferential processes versus action simulation. Curr. Biol. 17, 2117-2121.

Brazil, I. A., Mars, R. B., Bulten, B. H., Buitelaar, J. K., Verkes, R. J., and De Bruijn, E. R. (2011). A neurophysiological dissociation between monitoring one's own and others' actions in psychopathy. Biol. Psychiatry 69, 693-699.

Brüne, M. (2005). “Theory of mind” in schizophrenia: a review of the literature. Schizophr. Bull. 31, 21-42.
Bubic, A., von Cramon, D. Y., and Schubotz, R. I. (2010). Prediction, cognition and the brain. Front. Hum. Neurosci. 4, 25. doi: 10.3389/fnhum.2010.00025

Buckner, R. L., and Carroll, D. C. (2007). Self-projection and the brain. Trends Cogn. Sci. 11, 49-57.

Burke, C. J., Tobler, P. N., Baddeley, M., and Schultz, W. (2010). Neural mechanisms of observational learning. Proc. Natl. Acad. Sci. U.S.A. 107, 14431-14436.

Calvo-Merino, B., Glaser, D. E., Grezes, J., Passingham, R. E., and Haggard, P. (2005). Action observation and acquired motor skills: an fMRI study with expert dancers. Cereb. Cortex 15, 1243-1249.

Calvo-Merino, B., Grezes, J., Glaser, D. E., Passingham, R. E., and Haggard, P. (2006). Seeing or doing? Influence of visual and motor familiarity in action observation. Curr. Biol. 16, 1905-1910.

Campbell-Meiklejohn, D. K., Bach, D. R., Roepstorff, A., Dolan, R. J., and Frith, C. D. (2010). How the opinion of others affects our valuation of objects. Curr. Biol. 20, 1165-1170.

Capa, R. L., Marshall, P. J., Shipley, T. F., Salesse, R. N., and Bouquet, C. A. (2011). Does motor interference arise from mirror system activation? the effect of prior visuo-motor practice on automatic imitation. Psychol. Res. 75, 152-157.

Cardini, F., Costantini, M., Galati, G., Romani, G. L., Ladavas, E., and Serino, A. (2011). Viewing one's own face being touched modulates tactile perception: an fMRI study. J. Cogn. Neurosci. 23, 503-513.

Carp, J., Halenar, M. J., Quandt, L. C., Sklar, A., and Compton, R. J. (2009). Perceived similarity and neural mirroring: evidence from vicarious error processing. Soc. Neurosci. 4, 85-96.

Carter, C. S., Macdonald, A. W. 3rd., Ross, L. L., and Stenger, V. A. (2001). Anterior cingulate cortex activity and impaired self-monitoring of performance in patients with schizophrenia: an event-related fMRI study. Am. J. Psychiatry 158, 1423-1428.

Catmur, C., Walsh, V., and Heyes, C. (2009). Associative sequence learning: the role of experience in the development of imitation and the mirror system. Philos. Trans. R. Soc. Lond. B Biol. Sci. 364, 2369-2380.

Cattaneo, L., Barchiesi, G., Tabarelli, D., Arfeller, C., Sato, M., and Glenberg, A. M. (2011). One's motor performance predictably modulates the understanding of others' actions through adaptation of premotor visuo-motor neurons. Soc. Cogn Affect. Neurosci. 6, 301-310.

Centelles, L., Assaiante, C., Nazarian, B., Anton, J. L., and Schmitz, C. (2011). Recruitment of both the mirror and the mentalizing networks when observing social interactions depicted by pointlights: a neuroimaging study. PLoS ONE 6:e15749. doi: 10.1371/ journal.pone.0015749

Chang, L. J., Doll, B. B., Van 'T Wout, M., Frank, M. J., and Sanfey, A. G. (2010). Seeing is believing: trustworthiness as a dynamic belief. Cogn. Psychol. 61, 87-105.

Chartrand, T. L., and Bargh, J. A. (1999). The chameleon effect: the perception-behavior link and social interaction. J. Pers. Soc. Psychol. 76, 893-910.

Cheng, Y., Yang, C. Y., Lin, C. P., Lee, P. L., and Decety, J. (2008). The perception of pain in others suppresses somatosensory oscillations: a magnetoencephalography study. Neuroimage 40, 1833-1840.

Chong, T. T., Cunnington, R., Williams, M. A., Kanwisher, N., and Mattingley, J. B. (2008) fMRI adaptation reveals mirror neurons in human inferior parietal cortex. Curr. Biol. 18 1576-1580.

Coles, M. G. (1989). Modern mind-brain reading: psychophysiology, physiology, and cognition. Psychophysiology 26, 251-269.

Cook, R., Bird, G., Lunser, G., Huck, S., and Heyes, C. (2012). Automatic imitation in a strategic context: players of rock-paper-scissors imitate opponents' gestures. Proc. Biol. Sci. 279, 780-786.

Cook, J., and Bird, G. (2011). Social attitudes differentially modulate imitation in adolescents and adults. Exp. Brain Res. 211, 601-612.

Cooper, J. C., Dunne, S., Furey, T., and O'Doherty, J. P. (2012). Human dorsal striatum encodes prediction errors during observational learning of instrumental actions. J. Cogn. Neurosci. 24, 106-118.

Corlett, P. R., Taylor, J. R., Wang, X. J., Fletcher, P. C., and Krystal, J. H. (2010). Toward a neurobiology of delusions. Prog. Neurobiol. 92, 345-369.

Cross, E. S., Kraemer, D. J., Hamilton, A. F., Kelley, W. M., and Grafton, S. T. (2009). Sensitivity of the action observation network to physical and observational learning. Cereb. Cortex 19, 315-326.

Daprati, E., Franck, N., Georgieff, N., Proust, J., Pacherie, E., Dalery, J., and Jeannerod, M. (1997)
Looking for the agent: an investigation into consciousness of action and self-consciousness in schizophrenic patients. Cognition 65, 71-86.

Daunizeau, J., Den Ouden, H. E. Pessiglione, M., Kiebel, S. J., Stephan, K. E., and Friston, K. J. (2010). Observing the observer (I): meta-bayesian models of learning and decision-making. PLOS ONE 5:e15554. doi: 10.1371/journal. pone. 0015554

Davies, M., and Stone, T. (1995). Mental Simulation: Evaluations and Applications. Oxford: Blackwell Publishers.

De Bruijn, E. R., Schubotz, R. I., and Ullsperger, M. (2007). An event-related potential study on the observation of erroneous everyday actions. Cogn. Affect. Behav. Neurosci. 7, 278-285.

De Bruijn, E. R., De Lange, F. P., Von Cramon, D. Y., and Ullsperger, M. (2009). When errors are rewarding. J. Neurosci. 29, 12183-12186.

De Bruijn, E. R., Mars, R. B., Bekkering, H., and Coles, M. G. (2012). Your mistake is my mistake ... or is it? behavioural adjustments following own and observed actions in cooperative and competitive contexts. $Q$. J. Exp. Psychol. (Hove) 65, 317-325.

De Lange, F. P., Roelofs, K., and Toni, I. (2007). Increased selfmonitoring during imagined movements in conversion paralysis. Neuropsychologia 45, 2051-2058.

De Lange, F. P., Spronk, M., Willems, R. M., Toni, I., and Bekkering, H. (2008). Complementary systems for understanding action intentions. Curr. Biol. 18, 454-457.

De Vignemont, F., and Haggard, P. (2008). Action observation and execution: what is shared? Soc. Neurosci. 3, 421-433.

Decety, J. (1996). Do imagined and executed actions share the same neural substrate? Brain Res. Cogn. Brain Res. 3, 87-93.

Decety, J., and Ickes, W. (2009). The Social Neuroscience of Empathy. Cambridge, MA: MIT Press.

Decety, J., and Sommerville, J. A. (2003). Shared representations between self and other: a social cognitive neuroscience view. Trends Cogn. Sci. 7, 527-533.

Dehaene, S., Posner, M. I., and Tucker, D. M. (1994). Localization of a neural system for error detection and compensation. Psychol. Sci. 3, 303-305.

Delgado, M. R., Frank, R. H., and Phelps, E. A. (2005). Perceptions of moral character modulate the neural systems of reward during 
the trust game. Nat. Neurosci. 8, 1611-1618.

Delgado, M. R., Li, J., Schiller, D., and Phelps, E. A. (2008). The role of the striatum in aversive learning and aversive prediction errors. Philos. Trans. R. Soc. Lond. B Biol. Sci. 363, 3787-3800.

Dinstein, I., Hasson, U., Rubin, N., and Heeger, D. J. (2007). Brain areas selective for both observed and executed movements. J. Neurophysiol. 98, 1415-1427.

Driver, J., Davis, G., Ricciardelli, P., Kidd, P., Maxwell, E., and BaronCohen, S. (1999). Gaze perception triggers reflexive visuospatial orienting. Vis. Cogn. 6, 509-540.

Engel, A., Burke, M., Fiehler, K., Bien, S., and Rosler, F. (2008). Motor learning affects visual movement perception. Eur. J. Neurosci. 27, 2294-2302.

Evans, S., Fleming, S. M., Dolan, R. J., and Averbeck, B. B. (2011). Effects of emotional preferences on valuebased decision-making are mediated by mentalizing and not reward networks. J. Cogn. Neurosci. 23, 2197-2210.

Falkenstein, M., Hohnsbein, J., Hoormann, J., and Blanke, L. (1990). "Effects of errors in choice reaction tasks on the ERP under focused and divided attention," in Psychophysiological Brain Research, eds. C. H. M. Brunia, A. W. K. Gaillard, and A. Kok (Tilburg: Tilburg University Press), 192-195.

Fehr, E., and Camerer, C. F. (2007). Social neuroeconomics: the neural circuitry of social preferences. Trends Cogn. Sci. 11, 419-427.

Feinberg, I. (1978). Efference copy and corollary discharge: implications for thinking and its disorders. Schizophr. Bull. 4, 636-640.

Feldman, H., and Friston, K. J. (2010). Attention, uncertainty, and freeenergy. Front. Hum. Neurosci. 4:215. doi: 10.3389/fnhum.2010.00215

Ferri, F., Campione, G. C., Dalla Volta, R., Gianelli, C., and Gentilucci, M. (2011). Social requests and social affordances: how they affect the kinematics of motor sequences during interactions between conspecifics. PLoS ONE 6:e15855. doi: 10.1371/journal.pone.0015855

Fletcher, P. C., and Frith, C. (2009). Perceiving is believing: a bayesian approach to explaining the positive symptoms of schizophrenia. Nat. Rev. Neurosci. 10, 48-58.

Fliessbach, K., Weber, B., Trautner, P., Dohmen, T., Sunde, U., Elger, C. E., and Falk, A. (2007). Social comparison affects reward-related brain activity in the human ventral striatum. Science 318, 1305-1308.

Ford, J. M., and Mathalon, D. H. (2004). Electrophysiological evidence of corollary discharge dysfunction in schizophrenia during talking and thinking. J. Psychiatr. Res. 38, 37-46.

Forgiarini, M., Gallucci, M., and Maravita, A. (2011). Racism and the empathy for pain on our skin. Front. Psychol. 2:108. doi: 10.3389/fpsyg.2011.00108

Fourneret, P., Franck, N., Slachevsky, A., and Jeannerod, M. (2001). Self-monitoring in schizophrenia revisited. Neuroreport 12, 1203-1208.

Franck, N., Farrer, C., Georgieff, N., Marie-Cardine, M., Dalery, J., D'Amato, T., and Jeannerod, M. (2001). Defective recognition of one's own actions in patients with schizophrenia. Am. J. Psychiatry 158, 454-459.

Friesen, C. K., and Kingstone, A. (1998). The eyes have it! Reflexive orienting is triggered by nonpredictive gaze. Psychon. B Rev. 5, 490-495.

Friston, K. (2005). A theory of cortical responses. Philos. Trans. R. Soc. Lond. B Biol. Sci. 360, 815-836.

Friston, K., Kilner, J., and Harrison, L. (2006). A free energy principle for the brain. J. Physiol. Paris 100, 70-87.

Friston, K. (2008). Hierarchical models in the brain. PLoS Comput. Biol. 4:e1000211. doi: 10.1371/journal.pcbi. 1000211

Friston, K. J., Daunizeau, J., and Kiebel, S. J. (2009). Reinforcement learning or active inference? PLoS ONE 4:e6421. doi: 10.1371/journal.pone.0006421

Friston, K., and Kiebel, S. (2009). Cortical circuits for perceptual inference. Neural Netw. 22, 1093-1104.

Friston, K. J., Daunizeau, J., Kilner, J., and Kiebel, S. J. (2010). Action and behavior: a free-energy formulation. Biol. Cybern. 102, 227-260.

Friston, K., Mattout, J., and Kilner, J. (2011). Action understanding and active inference. Biol. Cybern. 104, 137-160.

Furl, N., Van Rijsbergen, N. J., Treves, A., Friston, K. J., and Dolan, R. J. (2007). Experience-dependent coding of facial expression in superior temporal sulcus. Proc. Natl. Acad. Sci. U.S.A. 104, 13485-13489.

Gallese, V., Fadiga, L., Fogassi, L., and Rizzolatti, G. (1996). Action recognition in the premotor cortex. Brain 119(Pt 2), 593-609.

Gazzola, V., and Keysers, C. (2009). The observation and execution of actions share motor and somatosensory voxels in all tested subjects: single-subject analyses of unsmoothed fMRI data. Cereb. Cortex 19, 1239-1255.

Gazzola, V., Rizzolatti, G., Wicker, B., and Keysers, C. (2007). The anthropomorphic brain: the mirror neuron system responds to human and robotic actions. Neuroimage 35, 1674-1684.

Gentsch, A., and Schutz-Bosbach, S. (2011). I did it: unconscious expectation of sensory consequences modulates the experience of self-agency and its functional signature. J. Cogn. Neurosci. 23, 3817-3828.

Gerull, F. C., and Rapee, R. M. (2002). Mother knows best: effects of maternal modelling on the acquisition of fear and avoidance behaviour in toddlers. Behav. Res. Ther. 40, 279-287.

Gilbert, D. T., and Wilson, T. D (2007). Prospection: experiencing the future. Science 317, 1351-1354.

Gobbini, M. I., and Haxby, J. V. (2007). Neural systems for recognition of familiar faces. Neuropsychologia 45 , 32-41.

Guo, X., Zheng, L., Zhang, W., Zhu, L., Li, J., Wang, Q., Dienes, Z., and Yang, Z. (2011). Empathic neural responses to others' pain depend on monetary reward. Soc. Cogn. Affect. Neurosci. doi: 10.1093/scan/nsr034. [Epub ahead of print].

Goubert, L., Vlaeyen, J. W., Crombez, G., and Craig, K. D. (2011). Learning about pain from others: an observational learning account. J. Pain 12, 167-174.

Graf, M., Reitzner, B., Corves, C., Casile, A., Giese, M., and Prinz, W. (2007). Predicting point-light actions in real-time. Neuroimage 36(Suppl. 2), T22-T32.

Greene, J. D., Nystrom, L. E., Engell, A. D., Darley, J. M., and Cohen, J. D. (2004). The neural bases of cognitive conflict and control in moral judgment. Neuron 44, 389-400.

Greene, D. J., Mooshagian, E., Kaplan, J. T., Zaidel, E., and Iacoboni, M. (2009). The neural correlates of social attention: automatic orienting to social and nonsocial cues. Psychol. Res. 73, 499-511.

Grezes, J., and Decety, J. (2001). Functional anatomy of execution, mental simulation, observation, and verb generation of actions: a metaanalysis. Hum. Brain Mapp. 12, 1-19.

Grezes, J., Armony, J. L., Rowe, J., and Passingham, R. E. (2003). Activations related to "mirror" and "canonical" neurones in the human brain: an fMRI study. Neuroimage 18, 928-937.

Gruetzmacher, N., Panzer, S., Blandin, Y., and Shea, C. H. (2011). Observation and physical practice: coding of simple motor sequences. Q. J. Exp. Psychol. (Hove) 64, 1111-1123.

Han, S., Fan, Y., Xu, X., Qin, J., Wu, B., Wang, X., Aglioti, S. M., and Mao, L. (2009). Empathic neural responses to others' pain are modulated by emotional contexts. Hum. Brain Mapp. 30, 3227-3237.

Harbaugh, W. T., Mayr, U., and Burghart, D. R. (2007). Neural responses to taxation and voluntary giving reveal motives for charitable donations. Science 316, 1622-1625.

Hare, R. D. (1980). A research scale for the assessment of psychopathy in criminal populations. Pers. Indiv. Differ. 1, 111-119.

Hare, T. A., Camerer, C. F., Knoepfle, D. T., and Rangel, A. (2010). Value computations in ventral medial prefrontal cortex during charitable decision making incorporate input from regions involved in social cognition. J. Neurosci. 30, 583-590.

Harris, L. T., and Fiske, S. T. (2010). Neural regions that underlie reinforcement learning are also active for social expectancy violations. Soc. Neurosci. 5, 76-91.

Haruno, M., Wolpert, D. M., and Kawato, M. (2001). Mosaic model for sensorimotor learning and control. Neural Comput. 13, 2201-2220.

Haxby, J. V., Hoffman, E. A., and Gobbini, M. I. (2000). The distributed human neural system for face perception. Trends Cogn. Sci. 4, 223-233.

Hayes, S. J., Elliott, D., and Bennett, S. J. (2010). General motor representations are developed during actionobservation. Exp. Brain Res. 204, 199-206.

He, X., Lever, A. G., and Humphreys, G. W. (2011). Interpersonal memorybased guidance of attention is reduced for ingroup members. Exp. Brain Res. 211, 429-438.

Helsen, K., Goubert, L., Peters, M. L., and Vlaeyen, J. W. (2011). Observational learning and painrelated fear: an experimental study with colored cold pressor tasks. J. Pain 12, 1230-1239.

Heyes, C. (2001). Causes and consequences of imitation. Trends Cogn. Sci. 5, 253-261.

Heyes, C. (2011). What's social about social learning? J. Comp. Psychol. doi: 10.1037/a0025180. [Epub ahead of print]. 
Heyes, C. M., and Ray, E. D. (2000). What is the significance of imitation in animals? Adv. Stud. Behav. $29,215-245$.

Hickok, G. (2009). Eight problems for the mirror neuron theory of action understanding in monkeys and humans. J. Cogn. Neurosci. 21, 1229-1243.

Hoffmann, S., and Falkenstein, M. (2011). Predictive information processing in the brain: errors and response monitoring. Int. J. Psychophysiol. 83, 208-212.

Hollander, A., Jung, C., and Prinz, W. (2011). Covert motor activity on NoGo trials in a task sharing paradigm: evidence from the lateralized readiness potential. Exp. Brain Res. 211, 345-356.

Holroyd, C. B., and Coles, M. G. (2002). The neural basis of human error processing: reinforcement learning, dopamine, and the errorrelated negativity. Psychol. Rev. 109, 679-709.

Holroyd, C. B., Nieuwenhuis, S., Yeung, N., and Cohen, J. D. (2003). Errors in reward prediction are reflected in the event-related brain potential. Neuroreport 14, 2481-2484.

Hommel, B., Musseler, J., Aschersleben, G., and Prinz, W. (2001). The Theory of event coding (TEC): a framework for perception and action planning. Behav. Brain Sci. 24, 849-878. discussion 878-937.

Hosp, J. A., Pekanovic, A., RioultPedotti, M. S., and Luft, A. R. (2011). Dopaminergic projections from midbrain to primary motor cortex mediate motor skill learning. J. Neurosci. 31, 2481-2487.

Humphreys, G. W., and Bedford, J. (2011). The relations between joint action and theory of mind: a neuropsychological analysis. Exp. Brain Res. 211, 357-369.

Hygge, S., and Ohman, A. (1978). Modeling processes in the acquisition of fears: vicarious electrodermal conditioning to fear-relevant stimuli. J. Pers. Soc. Psychol. 36, 271-279.

Iacoboni, M. (2009). Imitation, empathy, and mirror neurons. Annu. Rev. Psychol. 60, 653-670.

Imamizu, H., and Kawato, M. (2008). Neural correlates of predictive and postdictive switching mechanisms for internal models. J. Neurosci. 28, 10751-10765.

Imamizu, H., and Kawato, M. (2009). Brain mechanisms for predictive control by switching internal models: implications for higher-order cognitive functions. Psychol. Res. 73, 527-544.
Ishai, A. (2008). Let's face it: it's a cortical network. Neuroimage 40, 415-419.

Itagaki, S., and Katayama, J. (2008). Self-relevant criteria determine the evaluation of outcomes induced by others. Neuroreport 19, 383-387.

Jackson, P. L., Brunet, E., Meltzoff, A. N., and Decety, J. (2006). Empathy examined through the neural mechanisms involved in imagining how I feel versus how you feel pain. Neuropsychologia 44, 752-761.

Jakobs, O., Wang, L. E., Dafotakis, M., Grefkes, C., Zilles, K., and Eickhoff, S. B. (2009). Effects of timing and movement uncertainty implicate the temporo-parietal junction in the prediction of forthcoming motor actions. Neuroimage 47, 667-677.

Jellema, T., Baker, C. I., Wicker, B. and Perrett, D. I. (2000). Neural representation for the perception of the intentionality of actions. Brain Cogn. 44, 280-302.

John, E. R., Chesler, P., Bartlett, F., and Victor, I. (1968). Observation learning in cats. Science 159, 1489-1491.

Jones, R. M., Somerville, L. H., Li, J., Ruberry, E. J., Libby, V., Glover, G., Voss, H. U., Ballon, D. J., and Casey, B. J. (2011). Behavioral and neural properties of social reinforcement learning. J. Neurosci. 31, 13039-13045.

Kang, S. K., Hirsh, J. B., and Chastee, A. L. (2010). Your mistakes are mine: self-other overlap predicts neural response to observed errors. J. Exp. Soc. Psychol. 4, 229-232.

Kapogiannis, D., Campion, P., Grafman, J., and Wassermann, E. M. (2008). Reward-related activity in the human motor cortex. Eur. J. Neurosci. 27, 1836-1842.

Kavaliers, M., Choleris, E., and Colwell, D. D. (2001). Learning from others to cope with biting flies: social learning of fear-induced conditioned analgesia and active avoidance. Behav. Neurosci. 115, 661-674.

Keysers, C., Kaas, J. H., and Gazzola, V. (2010). Somatosensation in social perception. Nat. Rev. Neurosci. 11, 417-428.

Kiebel, S. J., Von Kriegstein, K., Daunizeau, J., and Friston, K. J. (2009). Recognizing sequences of sequences. PLoS Comput. Biol. 5:e1000464. doi: 10.1371/journal. pcbi.1000464

Kilner, J. M., Vargas, C., Duval, S., Blakemore, S. J., and Sirigu, A. (2004). Motor activation prior to observation of a predicted movement. Nat. Neurosci. 7, 1299-1301.
Kilner, J. M., Friston, K. J., and Frith, C. D. (2007a). The mirrorneuron system: a bayesian perspective. Neuroreport 18, 619-623.

Kilner, J. M., Friston, K. J., and Frith, C. D. (2007b). Predictive coding: an account of the mirror neuron system. Cogn. Process. 8, 159-166.

Kilner, J. M., and Frith, C. D. (2008) Action observation: inferring intentions without mirror neurons. Curr. Biol. 18, R32-R33.

King-Casas, B., Tomlin, D., Anen, C. Camerer, C. F., Quartz, S. R., and Montague, P. R. (2005). Getting to know you: reputation and trust in a two-person economic exchange. Science 308, 78-83.

Kim, B. R., Liss, A., Rao, M., Singer, Z. and Compton, R. J. (2011). Social deviance activates the brain's errormonitoring system. Cogn. Affect. Behav. Neurosci. 12, 65-73.

Kim, H., Shimojo, S., and O’Doherty, J. P. (2006). Is avoiding an aversive outcome rewarding? neural substrates of avoidance learning in the human brain. PLoS Biol. 4:e233. doi: 10.1371/journal.pbio.0040233

Klucharev, V., Hytonen, K., Rijpkema, M., Smidts, A., and Fernandez, G. (2009). Reinforcement learning signal predicts social conformity. Neuron 61, 140-151.

Koban, L., Pourtois, G., Vocat, R., and Vuilleumier, P. (2010). When your errors make me lose or win: eventrelated potentials to observed errors of cooperators and competitors. Soc Neurosci. 5, 360-374.

Koelewijn, T., Van Schie, H. T., Bekkering, H., Oostenveld, R., and Jensen, O. (2008). Motor-cortical beta oscillations are modulated by correctness of observed action. Neuroimage 40, 767-775.

Konvalinka, I., Vuust, P., Roepstorff, A., and Frith, C. D. (2010). Follow you, follow me: continuous mutual prediction and adaptation in joint tapping. Q. J. Exp. Psychol. (Hove) 63, 2220-2230.

Konvalinka, I., Xygalatas, D., Bulbulia, J., Schjodt, U., Jegindo, E. M., Wallot, S., Van Orden, G., and Roepstorff, A. (2011). Synchronized arousal between performers and related spectators in a fire-walking ritual. Proc. Natl. Acad. Sci. U.S.A. 108, 8514-8519.

Kording, K. P., and Wolpert, D. M. (2004). Bayesian integration in sensorimotor learning. Nature 427, 244-247.

Knapska, E., Mikosz, M., Werka, T., and Maren, S. (2010). Social modulation of learning in rats. Learn. Mem. 17, 35-42.
Knoblich, G., Stottmeister, F., and Kircher, T. (2004). Self-monitoring in patients with schizophrenia. Psychol. Med. 34, 1561-1569.

Krajbich, I., Adolphs, R., Tranel, D., Denburg, N. L., and Camerer, C. F. (2009). Economic games quantify diminished sense of guilt in patients with damage to the prefrontal cortex. J. Neurosci. 29, 2188-2192.

Kühn, S., Muller, B. C., Van Der Leij, A., Dijksterhuis, A., Brass, M., and Van Baaren, R. B. (2011). Neural correlates of emotional synchrony. Soc. Cogn. Affect. Neurosci. 6, 368-374.

Lanzetta, J. T., and Englis, B. G. (1989). Expectations of cooperation and competition and their effects on observers' vicarious emotional responses. J. Pers. Soc. Psychol. 56, 543-554.

Lawrence, E. J., Shaw, P., Giampietro, V. P., Surguladze, S., Brammer, M. J., and David, A. S. (2006). The role of 'shared representations' in social perception and empathy: an fMRI study. Neuroimage 29, 1173-1184.

Li, J., Xiao, E., Houser, D., and Montague, P. R. (2009). Neural responses to sanction threats in two-party economic exchange. Proc. Natl. Acad. Sci. U.S.A. 106, 16835-16840.

Luft, A. R., and Schwarz, S. (2009). Dopaminergic signals in primary motor cortex. Int. J. Dev. Neurosci. 27, 415-421.

Ma, Q., Shen, Q., Xu, Q., Li, D., Shu, L., and Weber, B. (2011). Empathic responses to others' gains and losses: an electrophysiological investigation. Neuroimage 54, 2472-2480.

Manera, V., Becchio, C., Schouten, B., Bara, B. G., and Verfaillie, K. (2011). Communicative interactions improve visual detection of biological motion. PLoS ONE 6:e14594. doi: 10.1371/journal.pone.0014594

Marco-Pallares, J., Kramer, U. M., Strehl, S., Schroder, A., and Munte, T. F. (2010). When decisions of others matter to me: an electrophysiological analysis. BMC Neurosci. 11, 86.

Massen, C., and Prinz, W. (2009). Movements, actions and tool-use actions: an ideomotor approach to imitation. Philos. Trans. R. Soc. Lond. B Biol. Sci. 364, 2349-2358.

Mayr, E. (1974). Behavior programs and evolutionary strategies. Am. Sci. 62, 650-659.

Mazzola, V., Latorre, V., Petito, A., Gentili, N., Fazio, L., Popolizio, T., Blasi, G., Arciero, G., and Bondolfi, G. (2010). Affective response to a loved one's pain: insula activity as a function of individual 
differences. PLoS ONE 5:e15268. doi: 10.1371/journal.pone. 0015268

McNally, G. P., Johansen, J. P., and Blair, H. T. (2011). Placing prediction into the fear circuit. Trends Neurosci. 34, 283-292.

Meissner, C. A., and Brigham, J. C. (2001). Thirty years of investigating the own-race advantage in memory for faces: a meta-analytic review. Psychol. Public Policy Law 7, 3-35.

Meulders, A., Vansteenwegen, D., and Vlaeyen, J. W. (2011). The acquisition of fear of movement-related pain and associative learning: a novel pain-relevant human fear conditioning paradigm. Pain 152, 2460-2469.

Miles, L. K., Nind, L. K., and Macrae, C. N. (2010). Moving through time. Psychol. Sci. 21, 222-223.

Miles, L. K., Lumsden, J., Richardson, M. J., and Neil Macrae, C. (2011). Do birds of a feather move together? group membership and behavioral synchrony. Exp. Brain Res. 211, 495-503.

Mineka, S., Davidson, M., Cook, M., and Keir, R. (1984). Observational conditioning of snake fear in rhesus monkeys. J. Abnorm. Psychol. 93, 355-372.

Mineka, S., and Cook, M. (1993). Mechanisms involved in the observational conditioning of fear. J. Exp. Psychol. Gen. 122, 23-38.

Mitchell, J. P. (2009). Inferences about mental states. Philos. Trans. R. Soc. Lond. B Biol. Sci. 364, 1309-1316.

Molenberghs, P., Brander, C., Mattingley, J. B., and Cunnington, R. (2010). The role of the superior temporal sulcus and the mirror neuron system in imitation. Hum. Brain Mapp. 31, 1316-1326.

Molenberghs, P., Cunnington, R., and Mattingley, J. B. (2009). Is the mirror neuron system involved in imitation? a short review and metaanalysis. Neurosci. Biobehav. Rev. 33, 975-980.

Molenberghs, P., Cunnington, R., and Mattingley, J. B. (2012). Brain regions with mirror properties: a meta-analysis of 125 human fMRI studies. Neurosci. Biobehav. Rev. 36, 341-349.

Moll, J., Zahn, R., De Oliveira-Souza, R., Krueger, F., and Grafman, J. (2005). Opinion: the neural basis of human moral cognition. Nat. Rev. Neurosci. 6, 799-809.

Mori, M. (1970). The uncanny valley. Energy 7, 33-35.

Mukamel, R., Ekstrom, A. D., Kaplan, J., Iacoboni, M., and Fried, I. (2010). Single-neuron responses in humans during execution and observation of actions. Curr. Biol. 20, 750-756.
Muller, B. C., Kuhn, S., Van Baaren, R. B., Dotsch, R., Brass, M., and Dijksterhuis, A. (2011). Perspective taking eliminates differences in corepresentation of out-group members' actions. Exp. Brain Res. 211, 423-428.

Mundy, P., Sigman, M., Ungerer, J., and Sherman, T. (1986). Defining the social deficits of autism: the contribution of non-verbal communication measures. J. Child Psychol. Psychiatry 27, 657-669.

Munksgaard, L., Depassille, A. M., Rushen, J., Herskin, M. S., and Kristensen, A. M. (2001). Dairy cows' fear of people: social learning, milk yield and behaviour at milking. Appl. Anim. Behav. Sci. 73, 15-26.

Nawa, N. E., Nelson, E. E., Pine, D. S., and Ernst, M. (2008). Do you make a difference? social context in a betting task. Soc. Cogn. Affect. Neurosci. 3, 367-376.

Neri, P., Luu, J. Y., and Levi, D. M. (2006). Meaningful interactions can enhance visual discrimination of human agents. Nat. Neurosci. 9, 1186-1192.

Newman-Norlund, R. D., Ganesh, S., Van Schie, H. T., De Bruijn, E. R., and Bekkering, H. (2009). Selfidentification and empathy modulate error-related brain activity during the observation of penalty shots between friend and foe. Soc. Cogn. Affect. Neurosci. 4, 10-22.

Nieuwenhuis, S., Heslenfeld, D. J., Von Geusau, N. J., Mars, R. B., Holroyd, C. B., and Yeung, N. (2005). Activity in human reward-sensitive brain areas is strongly context dependent. Neuroimage 25, 1302-1309.

Niv, Y., Daw, N. D., and Dayan, P. (2006). Choice values. Nat. Neurosci. 9, 987-988.

Nunez Castellar, E., Notebaert, W., Van den Bossche, L., and Fias, W. (2011). How monitoring other's actions influences one's own performance. Exp. Psychol. 58, 499-508.

Oberman, L. M., Hubbard, E. M., Mccleery, J. P., Altschuler, E. L. Ramachandran, V. S., and Pineda, J. A. (2005). EEG evidence for mirror neuron dysfunction in autism spectrum disorders. Brain Res. Cogn. Brain Res. 24, 190-198.

Olsson, A., Nearing, K. I., and Phelps, E. A. (2007). Learning fears by observing others: the neural systems of social fear transmission. Soc. Cogn. Affect. Neurosci. 2, 3-11.

Orgs, G., Dombrowski, J. H., Heil, M., and Jansen-Osmann, P. (2008). Expertise in dance modulates alpha/beta event-related desynchronization during action observation Eur. J. Neurosci. 27, 3380-3384.
O’Toole, A. J., Deffenbacher, K. A. Valentin, D., and Abdi, H. (1994). Structural aspects of face recognition and the other-race effect. Mem Cognit. 22, 208-224.

Oztop, E., Wolpert, D., and Kawato, M. (2005). Mental state inference using visual control parameters. Brain Res. Cogn. Brain Res. 22, 129-151.

Pecenka, N., and Keller, P. E. (2011) The role of temporal prediction abilities in interpersonal sensorimotor synchronization. Exp. Brain Res. 211, 505-515.

Perrett, D. I., and Emery, N. J. (1994). Understanding the intentions of others from visual signals: neurophysiological evidence. Curr. Psychol. Cogn. 13, 683-694.

Perry, A., Bentin, S., Bartal, I. B. Lamm, C., and Decety, J. (2010). "Feeling" the pain of those who are different from us: modulation of EEG in the mu/alpha range. Cogn. Affect. Behav. Neurosci. 10, 493-504.

Prinz, W. (1997). Perception and action planning. Eur. J. Cogn. Psychol. 9, 129-154.

Radke, S., De Lange, F. P., Ullsperger, M., and De Bruijn, E. R. (2011). Mistakes that affect others: an fMRI study on processing of own errors in a social context. Exp. Brain Res. 211 , 405-413.

Rao, R. P., and Ballard, D. H. (1999). Predictive coding in the visual cortex: a functional interpretation of some extra-classical receptive-field effects. Nat. Neurosci. 2, 79-87.

Raymaekers, R., Wiersema, J. R., and Roeyers, H. (2009). EEG study of the mirror neuron system in children with high functioning autism. Brain Res. 1304, 113-121.

Rhodes, G., Tan, S., Brake, S., and Taylor, K. (1989). Expertise and configural coding in face recognition. Br. J. Psychol. 80(Pt 3), 313-331.

Rigoni, D., Polezzi, D., Rumiati, R., Guarino, R., and Sartori, G. (2010). When people matter more than money: an ERPs study. Brain Res. Bull. 81, 445-452.

Rilling, J., Gutman, D., Zeh, T., Pagnoni, G., Berns, G., and Kilts, C. (2002). A neural basis for social cooperation. Neuron 35, 395-405.

Rilling, J. K., Sanfey, A. G., Aronson, J. A., Nystrom, L. E., and Cohen, J. D. (2004). Opposing BOLD responses to reciprocated and unreciprocated altruism in putative reward pathways. Neuroreport 15, 2539-2543.

Rushworth, M. F., Mars, R. B., and Summerfield, C. (2009). General mechanisms for making decisions? Curr. Opin. Neurobiol. 19, 75-83.
Sallet, J., Mars, R. B., Noonan, M. P., Andersson, J. L., O’Reilly, J. X., Jbabdi, S., Croxson, P. L., Jenkinson, M., Miller, K. L., and Rushworth, M. F. (2011). Social network size affects neural circuits in macaques. Science 334, 697-700.

Sanfey, A. G., Rilling, J. K., Aronson, J. A., Nystrom, L. E., and Cohen, J. D. (2003). The neural basis of economic decision-making in the ultimatum game. Science 300, 1755-1758.

Sartori, L., Becchio, C., Bara, B. G., and Castiello, U. (2009a). Does the intention to communicate affect action kinematics? Conscious. Cogn. 18, 766-772.

Sartori, L., Becchio, C., Bulgheroni, M., and Castiello, U. (2009b). Modulation of the action control system by social intention: unexpected social requests override preplanned action. J. Exp. Psychol. Hum. Percept. Perform. 35, 1490-1500.

Saygin, A. P., Chaminade, T., Ishiguro, H., Driver, J., and Frith, C. (2012). The thing that should not be: predictive coding and the uncanny valley in perceiving human and humanoid robot actions. Soc. Cogn. Affect. Neurosci. 7, 413-422.

Schacter, D. L., and Addis, D. R. (2007). The cognitive neuroscience of constructive memory: remembering the past and imagining the future. Philos. Trans. R. Soc. Lond. B Biol. Sci. 362, 773-786.

Schlicht, E. J., Shimojo, S., Camerer, C. F., Battaglia, P., and Nakayama, K. (2010). Human wagering behavior depends on opponents' faces. PLoS ONE 5:e11663. doi: 10.1371/journal.pone.0011663

Schober, H., and Rentschler, I. (1972). Optische Täuschungen in Wissenschaft und Kunst. München: Heinz Moos Verlag.

Schubotz, R. I., and von Cramon, D. Y. (2002). Predicting perceptual events activates corresponding motor schemes in lateral premotor cortex: an fMRI study. Neuroimage 15, 787-796.

Schultz, W., and Dickinson, A. (2000). Neuronal coding of prediction errors. Annu. Rev. Neurosci. 23, 473-500.

Scully, D. M., and Newell, K. M. (1985). Observational learning and the acquisition of motor skills: toward a visual perception perspective. J. Hum. Mov. Stud. 11, 169-186.

Sebanz, N., Bekkering, H., and Knoblich, G. (2006). Joint action: bodies and minds moving together. Trends Cogn. Sci. 10, 70-76. 
Serino, A., Giovagnoli, G., and Ladavas, E. (2009). I feel what you feel if you are similar to me. PLoS ONE 4:e4930. doi: 10.1371/journal. pone. 0004930

Serino, A., Pizzoferrato, F., and Ladavas, E. (2008). Viewing a face (especially one's own face) being touched enhances tactile perception on the face. Psychol. Sci. 19, 434-438.

Sescousse, G., Redoute, J., and Dreher, J. C. (2010). The architecture of reward value coding in the human orbitofrontal cortex. J. Neurosci. 30, 13095-13104.

Seymour, B., Yoshida, W., and Dolan, R. (2009). Altruistic learning. Front. Behav. Neurosci. 3:23. doi: 10.3389/neuro.08.023.2009

Shane, M. S., Stevens, M., Harenski, C. L., and Kiehl, K. A. (2008). Neural correlates of the processing of another's mistakes: a possible underpinning for social and observational learning. Neuroimage 42, 450-459.

Shane, M. S., Stevens, M. C., Harenski, C. L., and Kiehl, K. A. (2009). Double dissociation between perspective-taking and empathic-concern as predictors of hemodynamic response to another's mistakes. Soc. Cogn. Affect. Neurosci. 4, 111-118.

Singer, T., Seymour, B., O’Doherty, J. P., Stephan, K. E., Dolan, R. J., and Frith, C. D. (2006). Empathic neural responses are modulated by the perceived fairness of others. Nature 439, 466-469.

Singh, F., Pineda, J., and Cadenhead, K. S. (2011). Association of impaired EEG mu wave suppression, negative symptoms and social functioning in biological motion processing in first episode of psychosis. Schizophr. Res. 130, 182-186.

Sinigaglia, C., and Rizzolatti, G. (2011). Through the looking glass: self and others. Conscious. Cogn. 20, 64-74.

Spengler, S., Brass, M., Kuhn, S., and Schutz-Bosbach, S. (2010). Minimizing motor mimicry by myself: self-focus enhances online action-control mechanisms during motor contagion. Conscious. Cogn. 19, 98-106.

Sperry, R. W. (1950). Neural basis of the spontaneous optokinetic response produced by visual inversion. J. Cogn. Neurosci. 43, 482-489.

Spoormaker, V. I., Andrade, K. C. Schroter, M. S., Sturm, A., GoyaMaldonado, R., Samann, P. G., and Czisch, M. (2011). The neural correlates of negative prediction error signaling in human fear conditioning. Neuroimage 54, 2250-2256.

Stahl, J., Wiese, H., and Schweinberger, S. R. (2010). Learning task affects ERP-correlates of the own-race bias, but not recognition memory performance. Neuropsychologia 48, 2027-2040.

Stephens, G. J., Silbert, L. J., and Hasson, U. (2010). Speaker-listener neural coupling underlies successful communication. Proc. Natl. Acad. Sci. U.S.A. 107, 14425-14430.

Suddendorf, T., Addis, D. R., and Corballis, M. C. (2009). Mental time travel and the shaping of the human mind. Philos. Trans. R. Soc. Lond. B Biol. Sci. 364, 1317-1324.

Tabibnia, G., Satpute, A. B., and Lieberman, M. D. (2008). The sunny side of fairness: preference for fairness activates reward circuitry (and disregarding unfairness activates self-control circuitry). Psychol. Sci. 19, 339-347.

Takahashi, H., Kato, M., Matsuura, M. Mobbs, D., Suhara, T., and Okubo, Y. (2009). When your gain is my pain and your pain is my gain: neural correlates of envy and schadenfreude. Science 323, 937-939.

Thabit, M. N., Nakatsuka, M. Koganemaru, S., Fawi, G., Fukuyama, H., and Mima, T. (2011). Momentary reward induce changes in excitability of primary motor cortex. Clin. Neurophysiol. 122, 1764-1770.

Thibaut, J. W., and Kelley, H. H. (1959). The Social Psychology of Groups. London, UK: Wiley.

Tinbergen, N. (1951). The Study of Instinct. New York, NY: Oxford University Press.

Tipper, C. M., Handy, T. C., Giesbrecht, B., and Kingstone, A. (2008). Brain responses to biological relevance. $J$. Cogn. Neurosci. 20, 879-891.

Tsakiris, M. (2008). Looking for myself: current multisensory input alters self-face recognition. PLoS ONE 3:e4040. doi: 10.1371/journal.pone.0004040

Turella, L., Erb, M., Grodd, W., and Castiello, U. (2009). Visual features of an observed agent do not modulate human brain activity during action observation. Neuroimage 46, 844-853.

Turner, M. S., Simons, J. S., Gilbert, S. J., Frith, C. D., and Burgess, P. W. (2008). Distinct roles for lateral and medial rostral prefrontal cortex in source monitoring of perceived and imagined events. Neuropsychologia 46, 1442-1453.

Valdesolo, P., and Desteno, D. (2011). Synchrony and the social tuning of compassion. Emotion 11, 262-266.

Valdesolo, P., Ouyang, J., DeSteno, D. (2010). The rhythm of joint action: synchrony promotes cooperative behavior. J. Exp. Soc. Psychol. 46, 693-695.

Van den Bos, E., and Jeannerod, M (2002). Sense of body and sense of action both contribute to selfrecognition. Cognition 85, 177-187.

Van Meel, C. S., and Van Heijningen, C. A. (2010). The effect of interpersonal competition on monitoring internal and external error feedback. Psychophysiology 47, 213-222.

Van Schie, H. T., Mars, R. B., Coles, M. G., and Bekkering, H. (2004). Modulation of activity in medial frontal and motor cortices during error observation. Nat. Neurosci. 7, 549-554.

Van 'T Wout, M., and Sanfey, A. G (2008). Friend or foe: the effect of implicit trustworthiness judgments in social decision-making. Cognition 108, 796-803.

von Holst, E., and Mittelstaedt, $\mathrm{H}$ (1950). Das Reafferenzprinzip (Wechselwirkungen zwischen Zentralnervensystem und Peripherie) Naturwissenschaften 37, 464-476.

Walker, P. M., and Tanaka, J. W. (2003). An encoding advantage for own-race versus other-race faces. Perception 32, 1117-1125.

Walter, W. G., Cooper, R., Aldridge, V. J., McCallum, W. C., and Winter A. L. (1964). Contingent negative variation: an electric sign of sensorimotor association and expectancy in the human brain. Nature 203, 380-384.

Webster, M. A., Kaping, D., Mizokami, Y., and Duhamel, P. (2004). Adaptation to natural facial categories. Nature 428, 557-561.

Wenke, D., Atmaca, S., Holländer, A., Baess, P., Liepelt, R., and Prinz W. (2011). What is shared in joint action? Issues of co-representation, response conflict, and agent identification. Rev. Phil. Psych. 2, 147-172.

Williams, J. M., Ellis, N. C., Tyers, C. Healy, H., Rose, G., and Macleod, A K. (1996). The specificity of autobiographical memory and imageability of the future. Mem. Cognit. 24, 116-125.

Wiltermuth, S. S., and Heath, C. (2009). Synchrony and cooperation. Psychol. Sci. 20, 1-5.
Wolpert, D. M., and Miall, R. C. (1996). Forward models for physiological motor control. Neural Netw. 9, 1265-1279.

Wolpert, D. M., Miall, R. C., and Kawato, M. (1998). Internal models in the cerebellum. Trends Cogn. Sci. 2, 338-347.

Wolpert, D. M., Doya, K., and Kawato, M. (2003). A unifying computational framework for motor control and social interaction. Philos. Trans. R. Soc. Lond. B Biol. Sci. 358, 593-602.

Yomogida, Y., Sugiura, M., Sassa, Y., Wakusawa, K., Sekiguchi, A., Fukushima, A., Takeuchi, H., Horie, K., Sato, S., and Kawashima, R. (2010). The neural basis of agency: an fMRI study. Neuroimage 50, 198-207.

Yoshida, W., Seymour, B., Friston, K. J., and Dolan, R. J. (2010). Neural mechanisms of belief inference during cooperative games. J. Neurosci. 30, 10744-10751.

Yu, R., and Zhou, X. (2006). Brain responses to outcomes of one's own and other's performance in a gambling task. Neuroreport 17, 1747-1751.

Zaki, J., Schirmer, J., and Mitchell, J. P. (2011). Social influence modulates the neural computation of value. Psychol. Sci. 22, 894-900.

Zwickel, J., Grosjean, M., and Prinz, W. (2010a). What part of an action interferes with ongoing perception? Acta Psychol. (Amst.) 134, 403-409.

Zwickel, J., Grosjean, M., and Prinz, W. (2010b). On interference effects in concurrent perception and action. Psychol. Res. 74, 152-171.

Conflict of Interest Statement: The authors declare that the research was conducted in the absence of any commercial or financial relationships that could be construed as a potential conflict of interest.

Received: 15 February 2012; accepted: 09 May 2012; published online: 24 May 2012.

Citation: Brown EC and Brüne M (2012) The role of prediction in social neuroscience. Front. Hum. Neurosci. 6:147. doi: 10.3389/fnhum.2012.00147 Copyright (c) 2012 Brown and Brüne. This is an open-access article distributed under the terms of the Creative Commons Attribution Non Commercial License, which permits non-commercial use, distribution, and reproduction in other forums, provided the original authors and source are credited. 